\title{
The Chitrakarini Temple of Bhubaneswar (Odisha, India): An Investigative Field Study
}

\author{
Santosh Kumar Jha \\ Senior Faculty, Leather Goods and Accessories Design Department, Footwear Design and \\ Development Institute, Noida, India. Email: handicraftdesigner@gmail.com
}

\begin{abstract}
Heritage architectural and sculptural expressions are self-explanatory documents, which carries its legacy along with the wheel of time. The Chitrakarini temple of Bhubaneswar is one among such precious monuments, where the then socio-culture knowledge and ideological hemispheres had taken its materialistic identity, through precisely crafted sculptural panoramic expressions. Material wise this temple-structure could be categorized as an example of stone architecture; and is located in the Old Town area of Bhubaneswar, which is the state capital city of Odisha state, India. Goddess Chitrakarini is being worshipped in this temple- as major deity. As the name "Chitrakarini" reflects, this is a temple of "Female Painter" or "Paintress of Life"- and is world's only known temple, which is dedicated to the goddess "Chitrakarini"- who is the divine sub-form of Goddess Saraswati- the deity of Knowledge in Hinduism. Therefore goddess Chitrakarini, establishes her identity as the goddess of Creative Intellectual Activities. This temple was built during CE 1238 to CE 1264 by one of the Vaishnav king of the Eastern Ganga Dynasty, Narasingh Dev-1. According to local religious and socio-cultural beliefs this monument is dedicated to worship and honor women's contribution towards the creation, management and maintenance of human life-cycles over this planet. But as observed, now a day this heritage monument is detreating due to multifold issues. This temple is declared as 'Monument Of National Importance', under the Ancient Monuments and Archaeological Sites E Remains Act' 1958. This paper critically investigates the present overall scenario of this temple.
\end{abstract}

Keywords: Temple Conservation, Conservation of Architectural Heritage, Conservation of Hindu Heritage Sites, Conservation of Indian Stone Sculptures, Stone Crafts Legacy in India, Hindu Architecture

\section{Introduction}

This paper is an outcome of observation based field study. This study encompasses the existing general condition of the Chitrakarini temple, and includes its Geographic Location of Chitrakarini temple, Historical background, Socio-cultural importance, Stone as primary constructional raw material, Temple structure, Precisely crafted stone sculptures and carvings, Sculptural and structural damage studies, Temple revival Initiatives and Significance of Chitrakarini temple in contemporary era etc.

This temple's architectural structure belongs to the Kalinga School of Architecture ${ }^{1}$. Stone had been used as the primary construction material and further enriched through highly skillfully crafted stone sculptures and/or stone murals and carrying approximately 900 years old existence with legacy in Old City area of Bhubaneswar. In present context, being the state capital city of Odisha, Bhubaneswar has its own remarkable political, administrative, cultural and economic

${ }^{1}$ (The Hindu, 2002)

(c) AesthetixMS 2018. This Open Access article is published under a Creative Commons Attribution Non-Commercial 4.0 International License (http://creativecommons.org/licenses/by-nc/4.o/), which permits non-commercial re-use, distribution, and reproduction in any medium, provided the original work is properly cited. For citation use the DOI. For commercial re-use, please contact editor@chitrolekha.com 
identity in India'. Chitrakarini Temple had been declared as a 'Monument Of National Importance', under the Ancient Monuments And Archaeological Sites E Remains Act' 1958, by the Government of India.

This heritage monument ${ }^{3}$ is geographically situated in the Old Town area of Bhubaneshwar. However, Bhubaneswar is considered as a divine city in Hindu Religion, and is recognized as Guptkashi ${ }^{4}$, i.e. the holy place, where God Shiv stays anonymously; but in contrast, the Chitrakarini Temple belongs to the Vaishnavism stream of Hinduism, and was built by the Narasingh Dev-1, who was also known as Narasimhadev-1, or as Langula Narasingha Dev-1. He was a Vaishnav king of Chodaganga Dynasty or Eastern Ganga Dynasty ${ }^{6}$ and ruled during CE 1238 to CE $1264^{7}$, so this temple's building time-line could identified as CE 1238 to CE 1264. Geographically this temple is situated merely around 300 meters away from the main entrance of the CE 615 to CE $11^{\text {th }}$ century built, Shaivism forum belonging- Lingraj Temple; which is sharing common boundary wall, with the Chitrakarini Temple. This temple is dedicated to worship goddess Saraswati $^{8}$ and honor the endless contributions made by the entire race of female towards human settlement over this planet.

\section{Purposes of Study}

Primary purpose of this study is to understand the dynamics of: (a.) The existing status of the sand stone constructed sculptural, architectural and artifacts in Chitrakarini temple; (b.) Identify and document present scenario of the monumental damages and identify conservational initiatives; and (c.) Contemporary significance to preserve this temple etc. Secondary purpose of this study is to attract further serious research and intervention activities in the direction of architectural and stone artifact conservation"; so that the Chitrakarini Temple, as well as other similar natured heritage temples of Bhubaneswar, like- Mahakaleswar Temple, Papnashini Temple, Yameshwar Temple and Bakreswar Temple etc. and numerous other temples could also be restored- before completely get destructed.

\section{Research Method}

\subsection{Process Followed}

This field study was done during 18.06.2017 to 24.06.2017. During this study, the primary set of data had been collected through field observation and interactions- based on a 'whatever it was' basis. For this purpose, different interviews and one-to-one meetings had been conducted in and around the Chitrakarini Temple. To supplement findings of this field study, researcher had also visited a few other nearby temples with similar and/or near similar structures available around Chitrakarini Temple, like- Mahakaleswar Temple, Papnashini Temple, Yameshwar Temple and Bakreswar Temple etc. and included such findings in this paper- as and when required. During compilation of this paper, collected data sets had been supplemented by different secondary and tertiary sources- to achieve clarity in thought. All photographs displayed in this paper had been

\footnotetext{
${ }^{2}$ (A.C.Pradhan, 2013)

3 (Raj N. , 2016)

4 (Srinivasji, 2017)

${ }^{5}$ (Sivanand, 1996)

${ }^{6}$ (Wikiwand, 2017)

7 (Wikimedia Foundation, Inc., 2017)

8 (Sanatan Society, 2017)

${ }^{9}$ (Eric Doehne, 2010)
} 
snapped by this researcher, using an Andoer ${ }^{\mathrm{TM}}$ R11080P, 15fps Full HD 24MP Digital Camera, with Anti-shake quality and ${ }_{4} \mathrm{X}$ w/UV Filter facility ${ }^{10}$. Different graphic software had been used in combination to generate compositions, provided in this paper. The local Odiya terminologies were collected and represented according to the interviewee's phonetic pronunciations- and as understood by this researcher, which had been further translated in its near suitable English equivalent using different online Odiya-English and English-Odiya translation tools.

\subsection{Disclaimer}

As this was a field observation based explorative research process, having direct and indirect relation with heritage, religious and socio-cultural beliefs; so, this researcher respectfully states, that his approach was purely holistic and not intended to attract any negative impact over any individual or group's religious, commercial and non-commercial or any other interest(s)- if any; and so this researcher will not be responsible for any damage caused. Latitude of this paper is holistically limited to the revival and conservation of the seriously detreating but surviving $13^{\text {th }}$ century built Chitrakarini Temple and its premises- so that this monument's present status could be improvised and conserved, so that this irrevocable heritage could be preserved for further generations. Further, as this was an observation based research work, supplemented by random discussion sessions with the then available resource persons available near studied sites; so, considerable intellectually differences may occur- as opinions may vary from person-to-person basis. However, this researcher had tried his level best to maintain the correctness and clarity of thought during data-collection, analysis and document compilation.

\section{Geographic Location of Chitrakarini Temple}

The online search tool, elevationmap had been used to record the geographic elevation data of Lingraj Temple- as the Chitrakarini Temple is merely approx. 350 meters away from the Lingraj Temple, so these findings could be used as common indicative data about the Chitrakarini Temple's geographical location. The received set of recorded geographical data was found as: Latitude- 20.23771 North, Longitude- 85.83429 East; while the recorded altitude was 31 meters or 101 feet from sea level.

\footnotetext{
${ }^{10}$ (Amazon.com, Inc., 1996-2017)

${ }^{11}$ (elevationmap.net: Worldwide Elevations)
} 


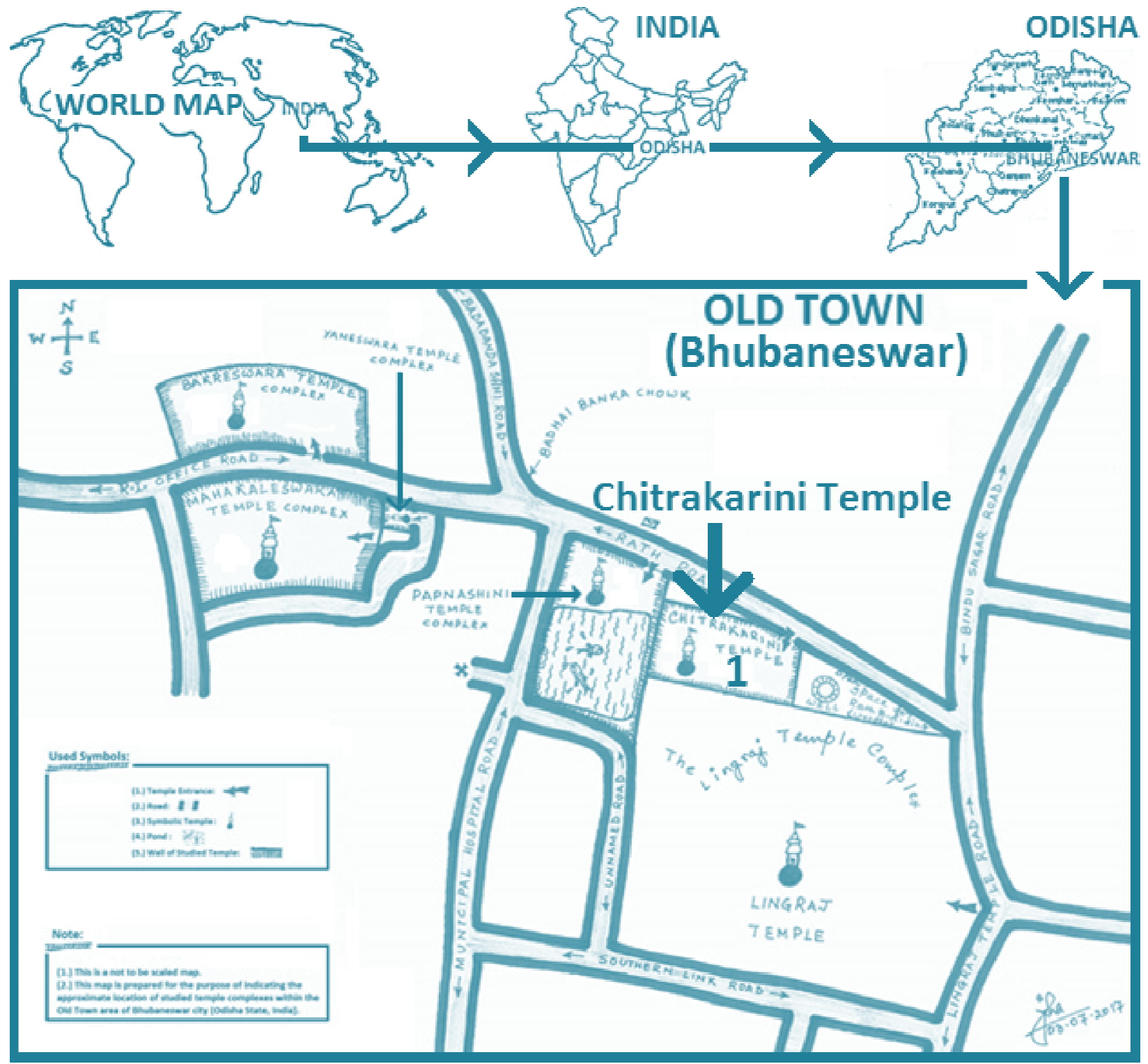

Image-1: Location map of the Chitrakarini Temple, in Old Town, Bhubaneswar, Odisha, India (Illustration by author)

\subsection{How to reach Chitakarini Temple?}

One may reach to the Chitrakarini temple from any corner of this planet. Temple's premise entrance was directly connected to the Badadanda Shahi Road. This road was situeted along with temple premise's East-North boundary. Temple premise's only entrance is situated at its NorthSouth corner. This road connects temple to the Kaplana Square- which could be considered as a major traffic hub of Bhubaneswar city. An approximate distance between Chitrakarini temple and Kaplana Square was about 03.5 kilometers. This distance could be travelled through locally available public and private transportation modes, like- shared auto rickshaw, city bus, taxi etc. A large number of economic-hotels were found available near Kaplana Square, where one may plan to stay, and explore smelling the genuine regional socio-cultural fragrances. 
For further travelling purposes, one may reach to the Biju Patnaik International Airport from the Kaplana Square, which was approx. 03.6 kilometers away- to travel through air-transport. The Bhubaneswar Railways Station was situated at a distance of approx. 01.1 kilometers from the Kaplana Square, and could be used to travel further through railways network. The Baramunda Bus Stand was situated at a distance of approx. 07.8 kilometers from the Kaplana Square, and could be used to travel further through road transport networks.

\section{Socio-Cultural Identity of Chitrakarini Temple}

This temple's name- "Chitrakarini Temple", reflects itself, that the main deity of this temples is Goddess Chitrakarini, whose idol is being worshipped here. "Chitrakarini" is a term, originated from the classic Indian language-Sanskrit, which could be equivalent in English language as "Paintress". "Chitrakarini"- is the 'constructional and explorative' form of Goddess Saraswati; who is regarded as the prime goddess of Knowledge and Creative Expressions ${ }^{12}$ according to Hinduism philosophy. As per the findings, goddess Chitrakarini, is a form of Saraswati; and through this form her, identity as the 'Goddess of Creative Expressions' had been established.

According to the local beliefs, devotees of the Chitrakarini goddess are worshipping, and celebrating the motherly feminine creative contributions towards building intellectually groomed human race over this planet. This is incredible!
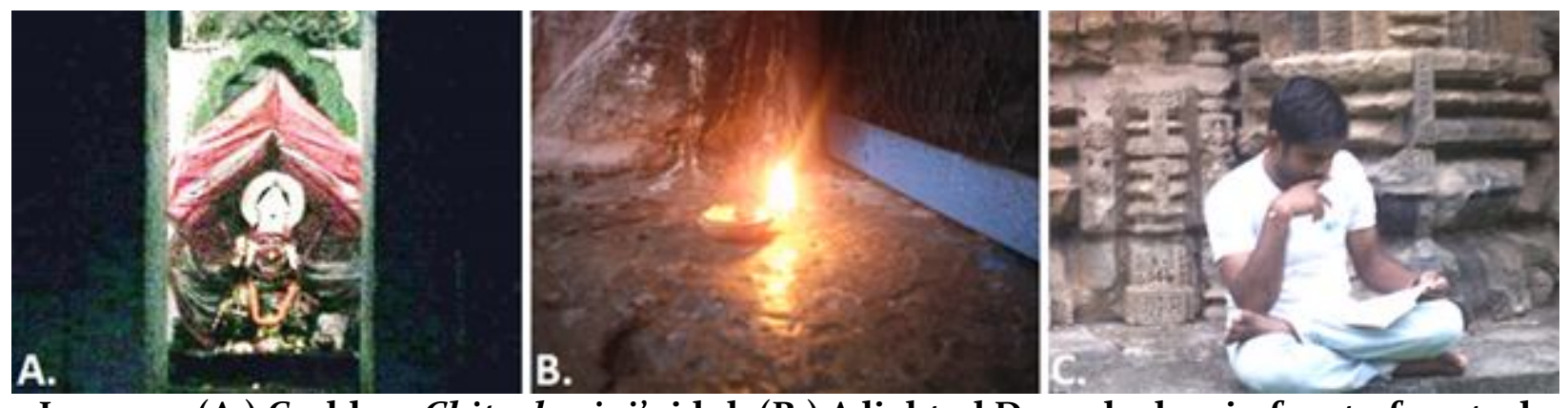

Image-2: (A.) Goddess Chitrakarini's idol, (B.) A lighted Deepak ghee in front of central shrine, (C.) A devotee, learning creative principles within the Chitrakarini Temple premises (Photography by author)

Here, this is important to discuss, that a few of the local devotees were also in believe, that the Goddess "Chitrakarini" is a form of Goddess Parwati ${ }^{13}$ - the wife of Lord Shiva, but this claim does not seems justifiable, as this Temple was built by a Vaishnav believing Ganga dynasty king, who ruled in this geographic region after Keshri dynasty; and both of the ruling dynasties were belonging from the then contraindicating religious-political and socio-cultural pathways of Vaishnavism $^{14}$ and Shaivism ${ }^{15}$. But in contemporary harmonious cultural and religious scenario of Hinduism in India, when differences between the Vaishnavism and Shaivism has almost forbidden and no such significant religious-political action group(s) are in powerful-existence; so, ambiguity of beliefs among believers in present era- regarding its actual belongingness with Vaishnavism or with Shaivism get faded. Resulting, few local devotees are worshipping Goddess "Chitrakarini"

\footnotetext{
12 (Wikimedia Foundation, Inc., 2017)

13 (Thakur, 2016)

${ }^{14}$ (The International Society for Krishna Consciousness (ISKCON), 2014)

${ }^{15}$ (Wikimedia Foundation, Inc., 2017)
} 
these days as a form of Mother Goddess Saraswati ${ }^{16}$ (Wife of Lord Brahma ${ }^{17}$, who belongs to Vaishnavism- as per the Hindu mythology Lord Brahma had taken birth from Lord Vishnu's navel zone $^{18}$ ); while others are worshiping Chitrakarini as the Mother Goddess Parwati (Wife of Lord Shiva). So, on the basis of this analytical understanding, this could be stated that the Goddess Chaitrakarini a form of Saraswati, who is belonging with the tradition of Vaishnavism. Further, as the Ganga dynasty Kings were strong followers of the Vaishnavism stream of Hinduism, and Vaishnavism followers had religious and socio-political conflicts with the Shaivism ${ }^{19}$ followers; so, there was no any logical interest for promoting a Ganga dynasty Kings to build such a beautiful Temple on their own costs, to promote a Goddess related with the Shaivism tradition, as the Chitrakarini in the then era ${ }^{20}$ of $13^{\text {th }}$ century. This speculative discussion is further evidenced and supported by the majority of sculpted forms of gods and goddesses precisely incorporated over the wall panels of this temple. In Chitrakarini temple, majority of the god and goddesses forms are belonging with the Vaishnavism stream of Hinduism and other closely knitted mythological forms, like- Garud, Seshnag, Narshingh etc.
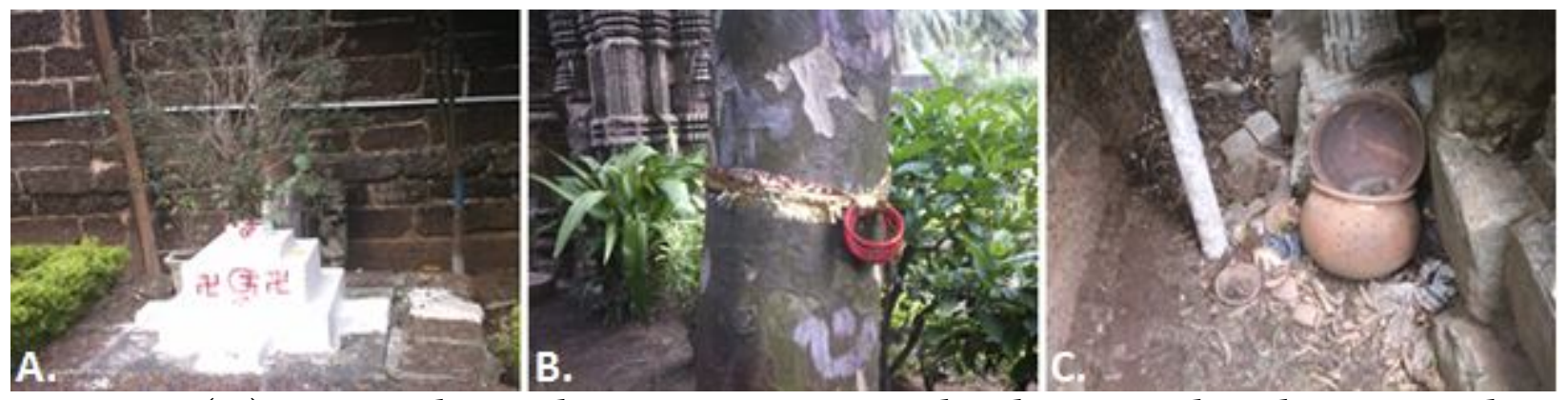

Image-3: (A.) A currently worshipping auspicious Tulsi Chaura in Chitrakarini Temple, with swastika symbols, (B.) A holy bunch of red Chudi taged by a newly wedded bride in a tree within temple premises, (C.) A set of terracotta made, used oil lighting system and utensils within the Chitrakarini Temple premises (Photography by author)

However, this temple has respectively less traffic of devotees. But this temple is a living temple, where the idol of the goddess Chitrakarini is being worshipped on a regular basis. This researcher had identified different worshipping marks, having deep values in Hinduism, as displayed in image-3.

\section{Primary construction material: Stone}

Stone was the basic construction material used in construction of Chitrakarini temple- foundation area, door panels, wall panels, boundary walls etc. all built using stone. Two different types of stone had been found in constructed structures, i.e., sandstone and laterite. Intricate Stone carvings were majorly available over sandstone panels. As noticed, originally this Temple had no provisions for a closeable door, but an Iron door had been installed later on at the common entrance of the main shrine- due to safety purposes.

\footnotetext{
${ }^{16}$ (Lotus Sculpture, 2000-2017)

17 (Wikimedia Foundation, Inc., 2017)

18 (G.M.Bailey, 1979, pp. 152-163)

${ }^{19}$ (Rakesh, 2013)

${ }^{20}$ (Gonda, 2016)
} 


\subsection{Sand Stone:}

Sandstones are nature made common sedimentary rocks, composed of sand particles, minerals and other locally available other variants ${ }^{21}$. Most of the Odisha sandstones are made up of the broken particles of the Deccan Plateau ${ }^{22}$, and are available in red, orange reddish yellow and pink etc. like colors variations. Sandstones of Odisha, carries clearly visible weather-marks or grain lines $^{23}$, and different types of coastal wind reactive components ${ }^{24}$. These stones are suitable for handcraft $^{25}$ and creative sculptural expression ${ }^{26}$ purposes through chiseling ${ }^{27}$ and other related craft processes. Probably that's why, sandstone had been used as the primary construction material for building Chitrakarini temple premise's all five shrines.
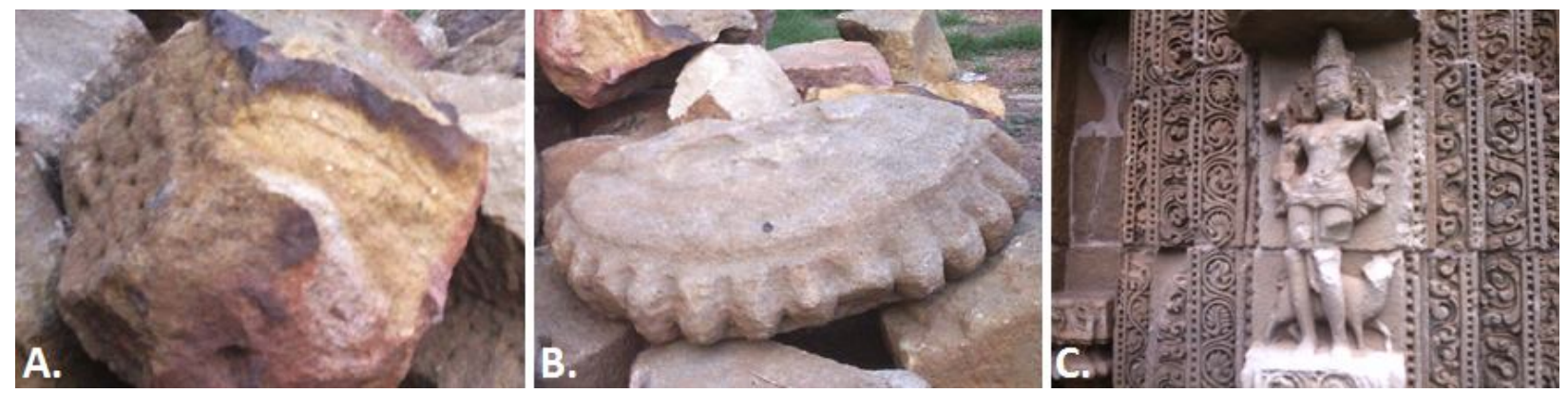

Image-4: (A.) Raw sandstone block, (B.) A carved sandstone block available in Mahakaleswar Temple premise, (C.) Sculpted sandstone wall of Chitrakarini Temple (Photography by author)

\subsection{Laterite Stone:}

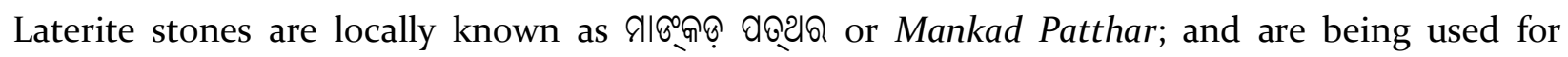
building contemporary houses as well used for other diversified daily life uses by the local residents. Few local uses of laterite bricks could be seen in image-5. Since long back, Laterite stone bricks had been used as a construction material ${ }^{28}$ in Odisha and so found used in constructions of the studied temples. Laterite decompositions are usually available near the earth crust, and are easy to be extracted, and further cutting into symmetric cuboidal bricks. There is a vast decomposition of laterite stone in different nearby locations within the Odisha sate.

\footnotetext{
${ }^{21}$ (Geology.com, 2005-2017)

22 (J.P.Shrivastava, 2005)

${ }^{23}$ (Shawe, 1968)

24 (Madhupratap, 2003)

25 (Harper Collins Publishers, 1853)

${ }^{26}$ (Jha, Sustenance of Languishing Traditional Crafts Through Design and Processes Interventions: Leather Toy Craft, 2015)

27 (Wikimedia Foundation, Inc., 2017)

${ }^{28}$ (Development Alternatives, 2012)
} 

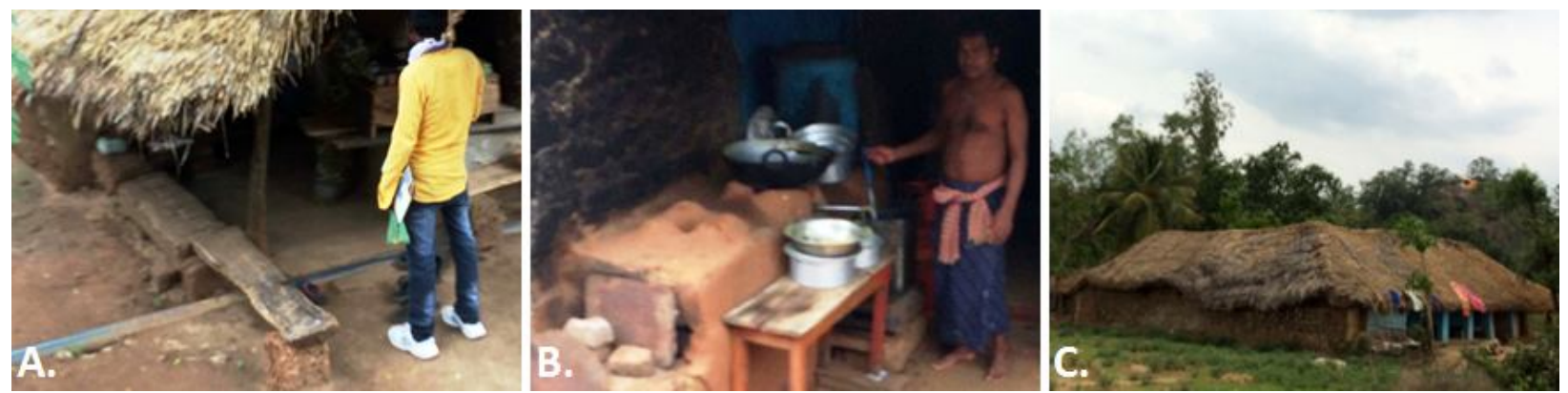

Image-5: Some native uses of laterite stone blocks: (A.) Used as seating base in a local tea stall along with flat wooden slabs, (B.) Laterite stone block made fireplace in a village restaurant-plastered with clay, (C.) A complete house made up of laterite blocks

(Photography by author)

The laterite bricks were mostly used for constructing external boundary walls of the studied temples in common- including Chitrakarini temple. However, as observed, few shrines were completely constructed using laterite bricks, with minimal carvings; please refer image-6(E\&F). These bricks had also been found used for constructing ladder steps, footpath constructions, and in wall constructions in different studied temples. As well these stones were also used for the purposes of wall repair and reinforcement in these temples- where original walls got poorly damaged.
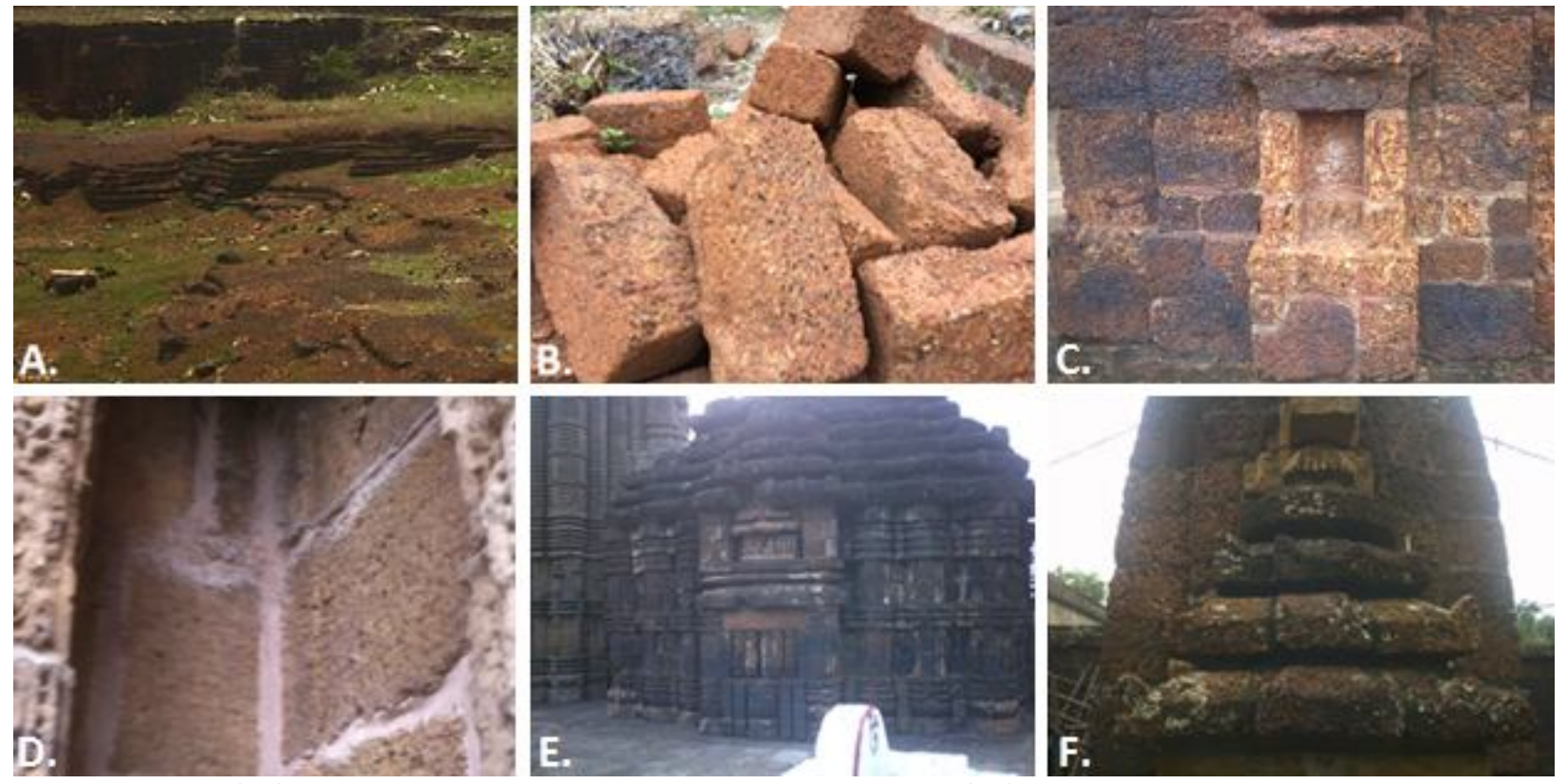

Image-6: (A.) Post-extracted view of a laterite mine, (B.) Rectangular-cuboidal brick blocks of laterite, (C.) A Laterite constructed complete wall panel in Papnashini Temple premise, (D.) A wall panel of Chitrakarini Temple restored using laterite bricks, (E.)

Papnashini Temple's entire Jagmohan shrine built using laterite bricks, (F.) A complete peripheral shrine in Mahakaleswar Temple campus built using laterite bricks (Photography by author)

A hammer-test had been done by this researcher, using two near-equal-volume blocks of postsculpt left-out sandstone and laterite stone available near a stone sculpting workshop, situated in 
Samantarapur area ${ }^{29}$ of Bhubaneswar, and found that strength-wise sandstone was at least 10-11 times stronger than its laterite equivalent. The major reason of this strength-difference was sample stone block's natural inter-particle space ${ }^{30}$ composition. The inter-particle space had been founder denser in sandstone rather than laterite. In addition to this inter-particle compositional character- laterite block was full of random formed stomas and was easily permeable for water, moisture and air. Due to laterite block's vast porous and rustic surface, this was highly difficult to identify seasoning grain marks over its surface; however identifying seasoning grain marks over the sandstone block was visually prominent. And so, this researcher had identified sandstone more feasible, rather than laterite for building any permanent structure. However, in nearby local market, laterite is available in abundance and also respectively cheaper in cost, rather than sandstone.

\section{Temple Structure}

As observed, the architectural structure of Chitrakarini temple could be categorized as a Panchayatana ${ }^{31}$ style of temple complex. Structurally this temple has five different shrines- main shrine is constructed in the center, where the idol of Goddess Chitrkarini's had been established at its Mulsthan. This section was found directly attached with the Jagmohan ${ }^{32}$; and remaining four temples were situated at the peripheral corners in rectangular alignment- keeping main temple in center. Main shrine of Chitrakarini Temple was east facing. External walls of all five temples were precisely carved with high craftsmanship precision. The major construction material had been identified as sandstone. The Ashlar Masonry Technique ${ }^{33}$ had been executed to construct this temple. Architectural structure of this temple belongs to the Kalinga Style of Architecture ${ }^{34}$. The main temple of Chitrakarini temple premise could be separated in two structural parts, i.e. Rekha Deul and Jagmohan ${ }^{35}$.

The Rekha Deul or $6661 /$ 968m was the tallest structure found in Chitrakarini Temple complex; where the major idol was being kept and worshipped by the senior most priest or Nonna ${ }^{36}$ or Я/ด्SI of this temple. The space within the Rekha Deul, where, idol of the major deity is being kept is called as- 6จุดูด or Garbhgrih or Sanctuary. In vertical axis, the entire structure of Rekha Deul could be subdivided into four major sub-sections, i.e., Kalash or ब/m6 or Top Most Section;

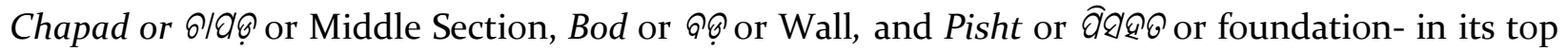
to bottom vertical alignment.

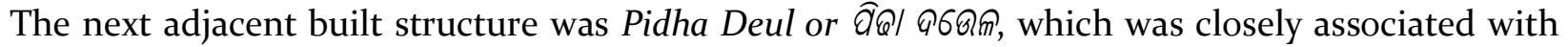
the Rekha Deul, and used for the purpose of main deity's worship by the pool of devotees. This space had been openly accessible by devotees, from where they could offer Bhajan ${ }^{37}$ or 9 @凡; Nrity or Яุọ; Devotional dance; perform meditation; and other ritualistic offerings to the deity. The structure of Pidha Deul includes four sub-sections in its vertical orientation, i.e., Ghanta-Kalash or

\footnotetext{
${ }^{29}$ (BIBHUTI BARIK, 2013)

${ }^{30}$ (George Hool, May, 1918, pp. 63-68)

${ }^{31}$ (Centre for Cultural Resources and Training, Ministry of Culture, Government of India, 2017)

32 (Rinku Parashar, March, 2016)

33 (B.C.Punmia, 1984, pp. 221-224)

34 (Wikimedia Foundation, Inc., 2017)

35 (Culture Department, Government of Odisha, 2015)

${ }^{36}$ (Sri Radha Mahalkshmi Ashram, Vrindaban, India, 2002)

37 (Wikimedia Foundation, Inc., 2017)
} 


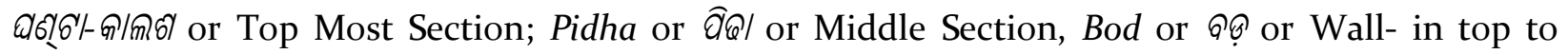
bottom constructed arrangement; and sharing common Pisht or $\widehat{\partial} Q \Omega \odot$ or foundation with the Rekha Deul. The inside hall space is called as Jagmohan ${ }^{38}$.

Above main deity's temple structure was surrounded by four other respectively smaller, peripheral temples in rectangular peripheral-orientation. However, all of these four peripheral temples had similar constructed structures, had similar heights and widths from their inside and outside. These peripheral temples had been constructed for the purpose of worshipping alliance deities.

\section{Stone Sculptures of Chitrakarini Temple}

In Chitrakarini Temple, major stone carvings were available over its exterior spaces, like- Bod, Chapd and Kalash sections of the Rekha Deul and Pidha Deul of the central temple's shrine; and Rekha Deul of other four peripheral temple shrines. These sections were completely surrounded with numerous fine crafted stone legacies. Among these expressions along with different forms of gods and goddesses, different daily life activities had been expressed through human and animal forms and skillfully supplemented through nature inspired forms. The entire range of sculpted forms over the wall panels of Chitrakarini temple could be classified on the basis of explored subjects, into following five sub-sections according to their subjects- human daily life forms; human-animal forms; fused human and animal forms; creature forms; biological forms etc. However a sizable number of sculptures are now available in partially or completely damaged conditions.

\subsection{Sculpted forms based over human life:}

These stone sculptures were found exceptional in terms of expressed statements, involved skill sets and intellectual expressions of different Ras through the entire range of sculpted forms. There are eleven different Ras, as per the grammar of the classic Indian language Sanskrit, i.e., Shringar Ras, Hasy Ras, Karun Ras, Raudr Ras, Vir Ras, Bhayanak Ras, Vibhats Ras, Adbhut Ras, Shant Ras, Watsaly Ras and Bhakti Ras ${ }^{39}$ etc. All of the human forms are precisely crafted and ably expressing their individualistic statements, through their self-explanatory mode of expressions. Majority of the sculpted human forms of this temple are now in damaged conditions and in urgent requirement of restorative conservation ${ }^{40}$.
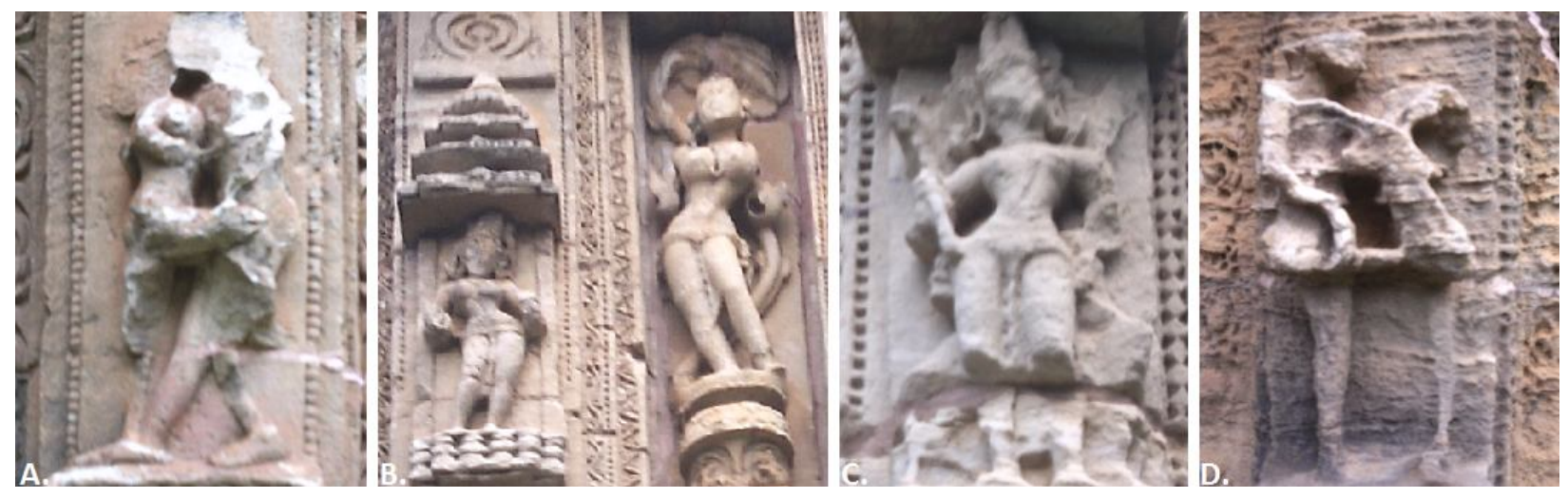

${ }^{38}$ (GKToday, 2014)

39 (Dubey, 2014)

${ }^{40}$ (National Archives of Mauritius, Republic of Mauritius, 2017) 
Image-7: (A.) Pair of human form with chiseled broken head, (B.) Two different leady forms in original condition displaying Hashy Ras and Shringar Ras, (C.) Half damaged lord Vishnu form displaying Vir Ras, (E.) Due to nature caused, local climatic conditions faded sculpture of unidentified human forms ${ }^{41}$ (Photography by author)

Sculptures displayed in image-7(A,C\&E) were found within 15 feet's vertical height range from the temple's foundation over wall panel; while the sculptures displayed in $7(B)$ were found above 15 feet's vertical height range from the Chitrakarini Temple foundation.

\subsection{Sculpted fused human-animal forms:}

Different fused human-animal Hindu mythological forms had also been found among the wall mounted sculptures in Chitrakarini Temple. A few of them were:

\subsubsection{God Narsing:}

God Narsing ${ }^{42}$ is considered as a Hindu god and is regarded as a form of lord Vishnu. In this mythological sculpture, lion's upper halves got fused with a human body. Please refer image-8(A).

\subsubsection{God Sheshnag and Vimla Devi or Nag-Lakshmi:}

God Sheshnag ${ }^{43}$ is a Hindu mythological snake god's form, having seven heads. In this mythological sculpture, human's upper half got fused with the Nag Snake's lower body part. In this temple, a wide range of different female snake forms had also been found sculptedrepresenting different forms of goddess Vimala Devi ${ }^{44}$ or Nag-Lakshmi ${ }^{45}$. She was the wife of Sheshnag; please refer image-8(B).

\subsubsection{God Garud:}

In Hinduism, God Garud ${ }^{4}$ had been considered among the prime support to lord Vishnu and considered as the most powerful king of birds. In a sculpted form, Garud's main body had been represented with two pair of wings on his back side, along with a bird's face which was fused with a human body. In this sculpture, face was found damaged and its beak part was lost. Please refer image-8(C).

\subsubsection{God Ganesh:}

In Hindu mythology, God Ganesh ${ }^{47}$ had been considered as a Hindu god who is equally regarded and worshipped in both the streams of Vaishnavism as well as in Shaivism. Even today, god Ganesh is equally being honored and worshipped along with Vaishnav goddess- Saraswati and Lakshmi, on the occasion of Deepawali ${ }^{4}$, in every Hindu family ${ }^{49}$. In a sculpted form, Ganesh's head part was sculpted as elephant head, while the remaining parts were sculpted as human body form. But interestingly, in this sculpture, an animated form of God Ganesh is riding over an

\footnotetext{
41 In image-9, 'A,C and E' are within 10 feet'

42 (Soifer, 1991, pp. 03-130)

${ }^{43}$ (Raj, 2009)

${ }^{44}$ (WordPress.com, 2016)

${ }^{45}$ ( tellyupdates.com, 2016)

${ }^{46}$ (Sumanta Sanyal, Encyclopedia Mythica, 1997)

47 (Brown, 1991)

48 (मुक्त ज्ञानकोश विकिपीडिया, 2017)

${ }^{49}$ (Chitgopekar, 2011-2014)
} 
elephant and not over a Rat! This is contraindicative with the popular Shivism style of Ganesh's representation, where God Ganesh get represented riding over a Rat! Please refer image-8(D).
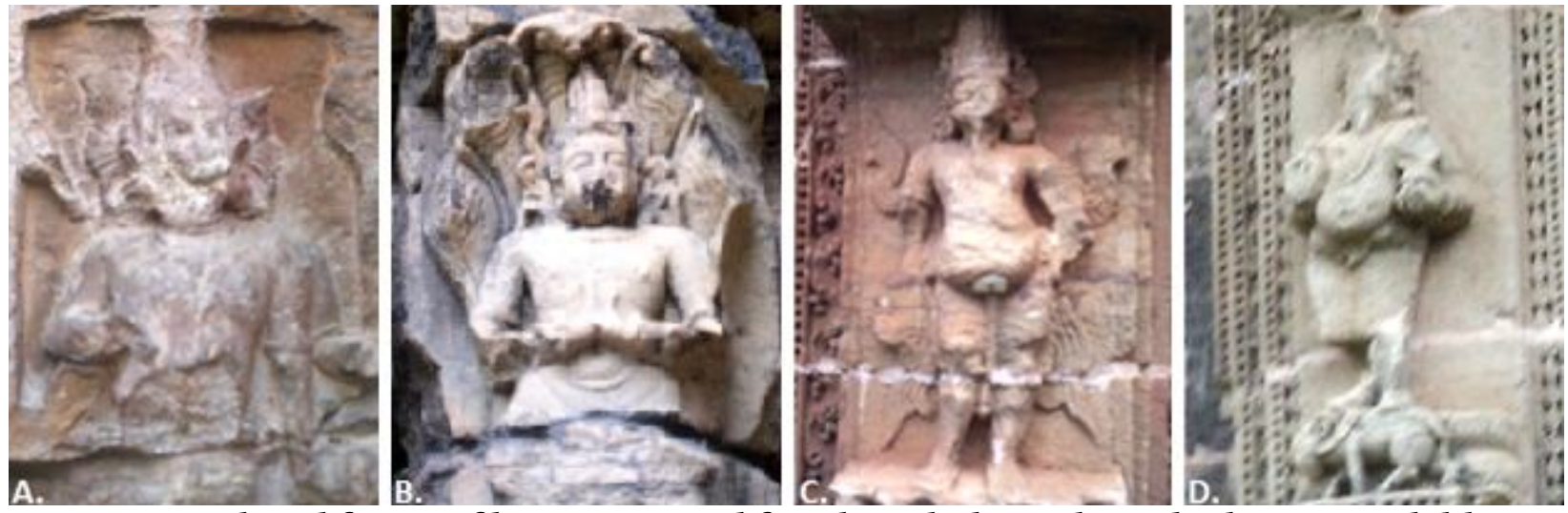

Image-8: Sculpted forms of human-animal fused mythological Hindu deities available on the walls of Chitrakarini Temple: (A.) God Narsing, (B.) God Shashnag, (C.) God Garud, and (D.) God Ganesh (Photography by author)

\subsection{Sculpted human and animal forms:}

In addition to above human-animal fused Hindu mythological forms, interactive human-animal forms had also been carefully sculpted over these wall panels. But as majority of the sculptures of this series, were found poorly damaged in Chitrakarini Temple, so this was quite difficult to identify the subjected form of deities. However, on the basis of studied body gestures of the subjected forms, this could be speculated, that in image-9, (A.) is a Pig similar form, (B.) is a Goat similar form, (C.) is a Monkey similar form, and (D.) is a Lion similar form etc. had been sculpted. The sculpture of elephant riding Ganesh could also be included in this series, please refer image$8(\mathrm{D})$.
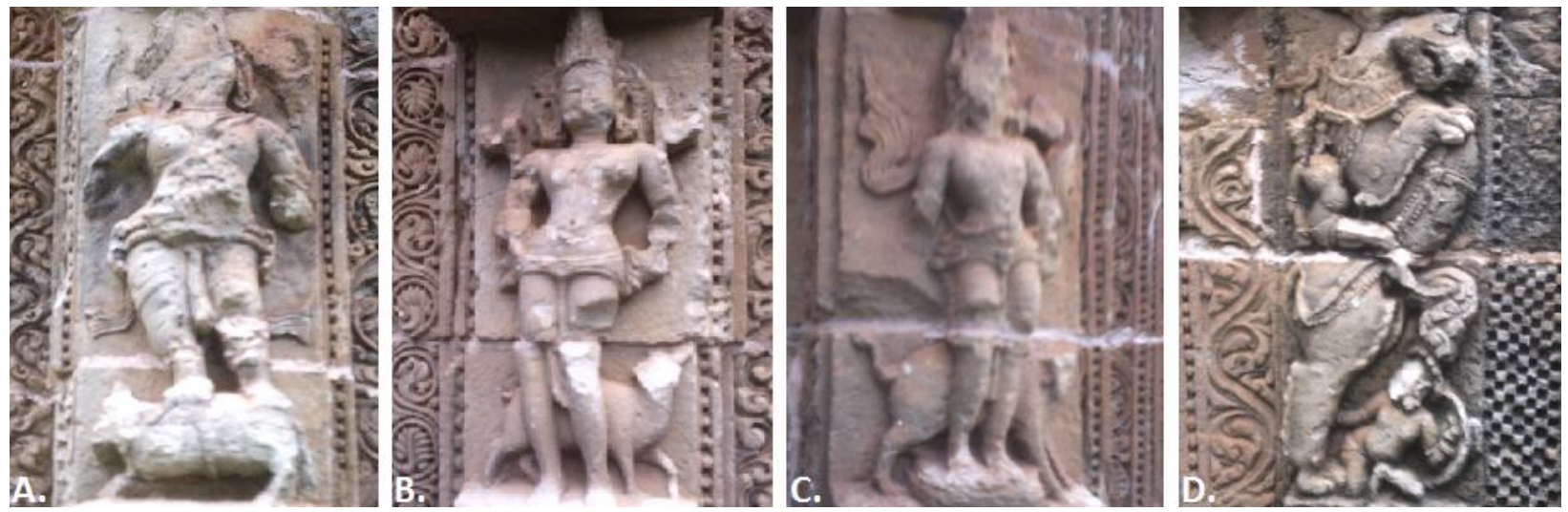

Image-9: Sculpted forms of human and animal interactive forms from the walls of

Chitrakarini Temple- (A.) Pig with man, (B.) Goat with man, (C.) Monkey with man, and (D.) Lion with two men (Photography by author)

\subsection{Creature forms:}

Like above discussed human and fused-human series, sculptures of this temple gave equal emphasis over the different daily-life activities of animal kingdom too. A few of the examples had been displayed in image-10. Different lively repeat-patterns in linear progression were available 
over this temple's wall panels. Creature's life in nature had been incorporated beautifully through image-10 (B,C\&D). The social interaction among creatures could be referred in $10(A \& G)$; where the copulative pair of creatures could be referred in image-10(E\&G).
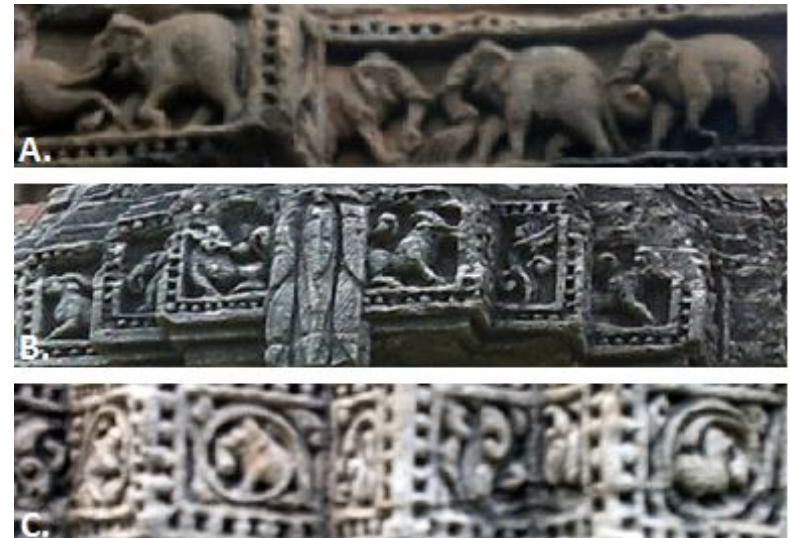
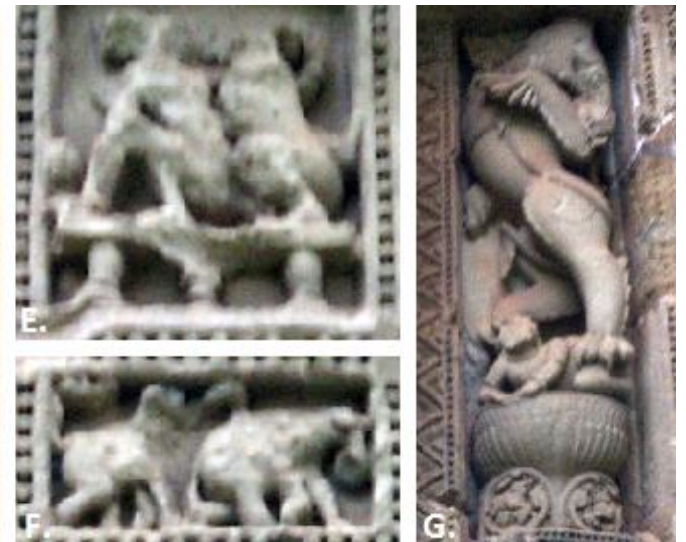

Image-10: Sculpted animal forms over the walls of Chitrakarini Temple- (A.) Interactive elephant series, (B.) Lion series, (C.) A miscellaneous series of fish, bird, lion and elephant, (D.) Bird series, (E.) Copulating pair of monkey, (F.) Copulating pair of elephant, and (G.) Garud standing over an unidentified creature (Photography by author)

Forms of different birds, and animals indulge in different lively activities were also found sculpted over these wall panels. Among other major sculpted subjects, elephant series, bird series, lion series, monkey series, deer series etc. had been found. All of these were quite lively, and were crafted precisely over the Chitrakarini temple's wall panels.

\subsection{Murals inspired from biological forms:}

Different biological and other forms were found over the wall panels of temple. These forms could be categorized as murals in majority of the cases, as most of them had been incorporated over two-dimensional stone slabs; which were further placed over the main temple's wall panels. However, few of them also had three dimensional characteristics as well, like image-11(G.); and so this panel could be considered as a wall mounted sculpture.
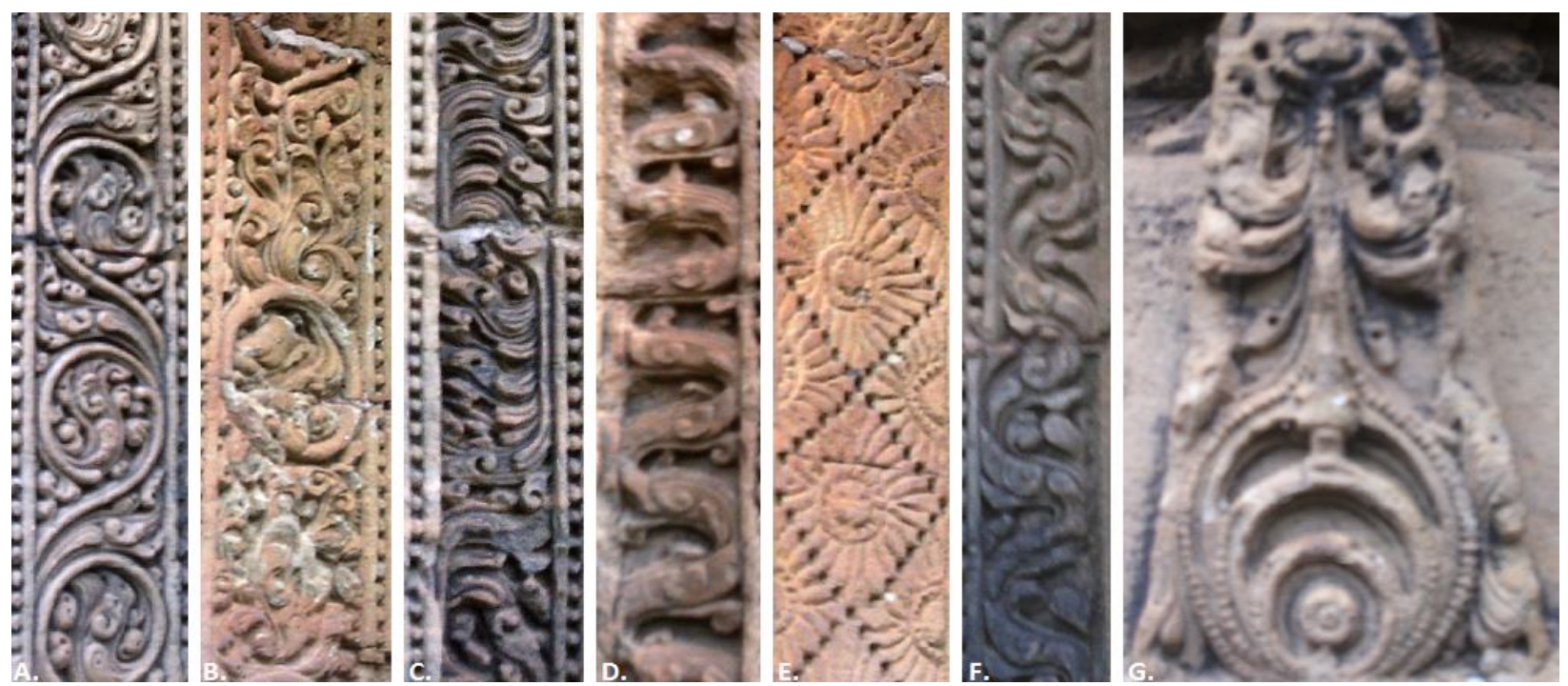
Image-11: Different panels carrying floral forms installed on Chitrakarini Temple walls (Photography by author)

The walls panels of Chitrakarini Temple were ably demonstrated as the great treasury of wall mounted murals. These murals were precisely chiseled and mounted all around the temple walls and carrying great legacy of stone craftsmanship of CE $13^{\text {th }}$ century. Mural panels displayed in images-11(A,B,C,E\&F) were inspired from different floral forms; while image-11(D) was inspired from the abdominal form of snake; while the form displayed in image-11 $(G)$ had been identified inspired from the vagina- the biological feminine reproductive organ.

\section{Damage Studies in Chitrakarini Temple}

\subsection{Factors responsible for present status of damages in Chitrakarini Temple}

Some of the identified responsible factors for the existing damages of sculptures, artifacts and architectural structures in Chitrakarini Temple could be classified into three broader sub-sections: (a.) Effects of local natural climate; (b.) Un-ethical activities; and (c.) Some improper incorporation of basic amenity enhancement initiatives in temple premises etc.

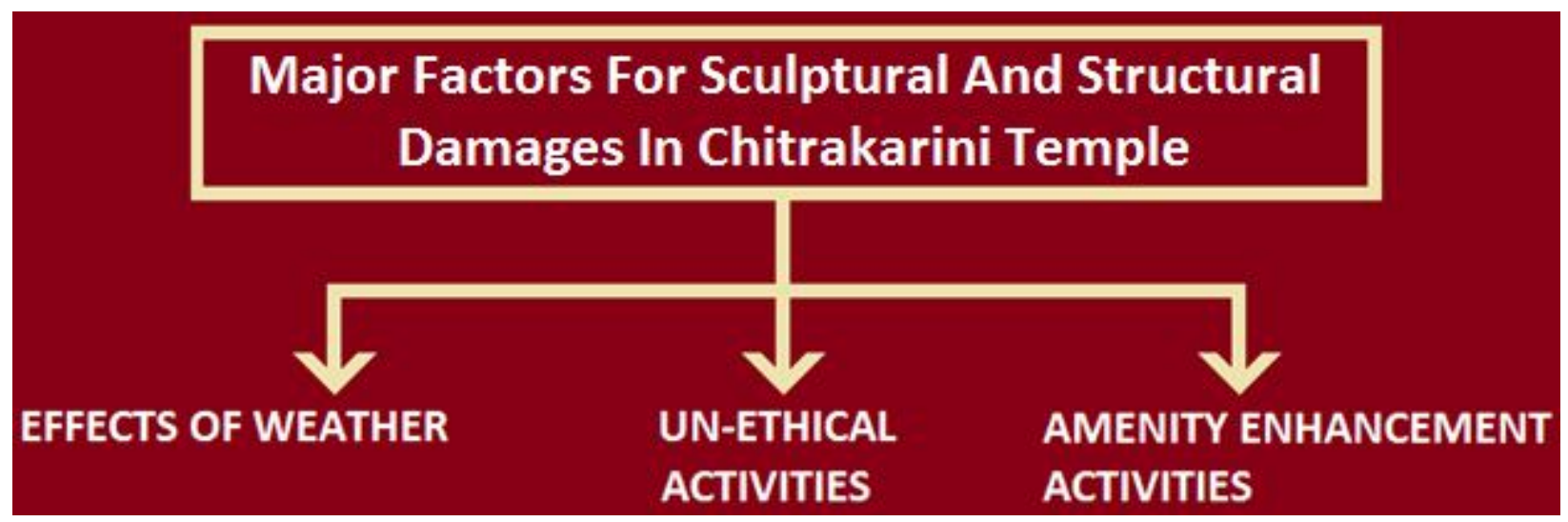

Image-12: causes of existing damages in Temple artifacts and structures in the Chitrakarini Temple Premises

9.2. Nature caused stone decay due to local atmospheric conditions

Due to the effects of local natural atmospheric conditions, decay of sandstone had been identified as one of the major aspect in this temple's foundation area damages ${ }^{50}$. Few of the climatic conditions generated stone decay effects were available over the wall panels; majority of them were spread near temple's foundation zone. However, due to local atmospheric conditions, sculptural decays in upper parts of Chitrakarini Temple had also been observed. In this context, a report titled- "Conservation of the Konarak Temple, Orissa" prepared by the United Nations Educational, Scientific And Cultural Organization, could be referred and its guidelines, as suggested by R.M. Lemaire and M. Tabasso ${ }^{51}$, could be precisely followed for conserving the overall architectural structure and artifacts of this temple.

\footnotetext{
${ }^{50}$ (Panda, 2011)

${ }^{51}$ (R.M. Lemaire, 1981)
} 

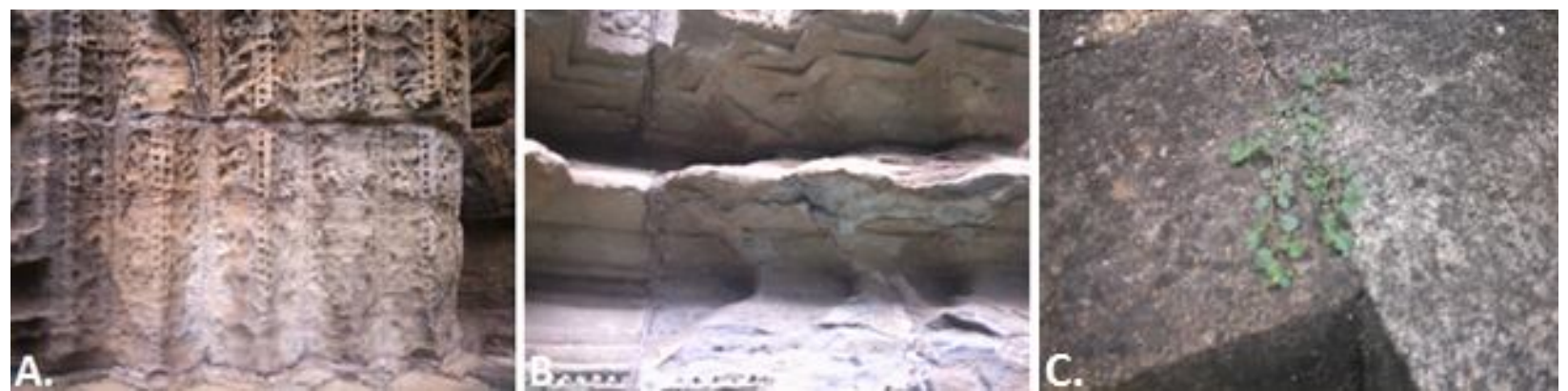

Image-13: (A.) A panel with climate-washed artifacts, (B.) A climate caused self-chipping stone structures near temple foundation, $(C$.) An example of growing plant from a stone block join of the main temple's foundation, which may cause further damages with its growing root strength inside this joint (Photography by author)

According to the above referred document, local atmospheric conditions affected the decay in upper and inner layers of the sculptural artifacts of this temple. These sculptures and architectural structures were found with poorly faded surfaces and the upper carved surfaces of these structures and sculptures were coming out in the form of dusts, and were attaining faded visual appearance and weakening internal structures. Some of the panels could be referred through image-13(A\&B). At several points, serious stone cracks had also been identified by this researcher.

Near lower foundation area, unwanted growth of plants between the stone-block joints had also been found; which is enough for these unwanted herbs to cause damages in the lower foundation area for Chitrakarini Temple's existing structure, which had travelled centuries long journey till date. An existing example of this factor is displayed through image-13(C), which is also an unignorably responsible factor for existing nature caused damages in lower foundational structures $^{52}$, along with the local atmospheric conditions.

\subsection{Un-Ethical Activities: Over Sculpted Stone Artifacts}

As per the local commuters, Chitrakarini and other nearby temples were surviving under high threat of monumental theft. This information is also supported by a journal publication titled"Monumental Neglect: Need for Awakening", published in Odisha Review ${ }^{53}$. In 2001, the similar case of heritage monument theft had come in notice from Lord Jagannath Temple of Puri in Odisha $^{54}$. As these incidences are projecting direct threat over the national heritage identity ${ }^{55}$.

\footnotetext{
52 (Yadav, 2015)

53 (P.K.Devi, 2011)

54 (Das, 2010)

55 (Harris, 2007, pp. 03-20)
} 

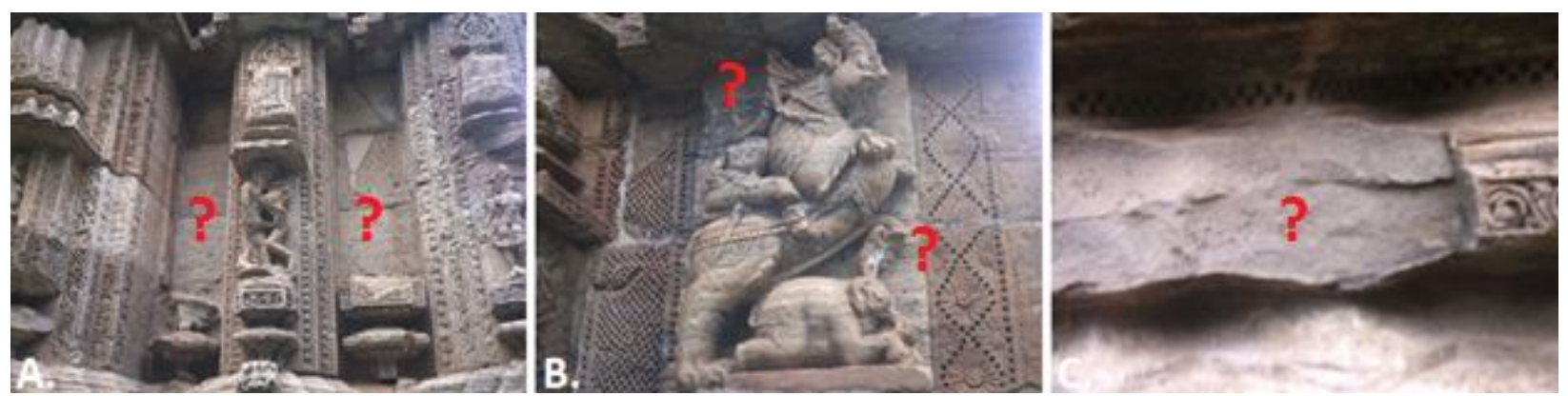

Image-14: (A.) A wall panel with two missing sculptures- Both bases remain, (B.) A deliberately half-damaged sculpture remain, (C.) A deliberately damaged panel with clearly visible chiseling marks (Photography by author)

Such unethical, unsocial practices should be completely prevented- as this researcher came across to that such incidences were disappointed the devotees ${ }^{56}$ of this temple. Preventing theft of artifacts will effectively contribute towards the conservation of Chitrakarini Temple's heritage and its socio-cultural identity.

\subsection{Unintentional damages caused by devotees}

This had also been found that during the ritual worship-practices, devotees had been touching and rubbing idols of gods and goddesses- by ignoring the fact, that such idols had been made up of a physical material, i.e., stone; and are representing the speculative physical form of such deity. On the wheel of long travelled time, such repetitive regular practice becomes responsible to cause effects of touch-wash ${ }^{57}$. As the Chitrakarini Temple and its stone-carved artifacts are of around 900 year's old now in 2017-2018; so, such faded effects on artifacts were now clearly visible over such regularly touched areas. Mostly these effects had been found over the sculptures, where the traffic of devotees was higher, like- the only entrance to this temple's Jagmohan area.

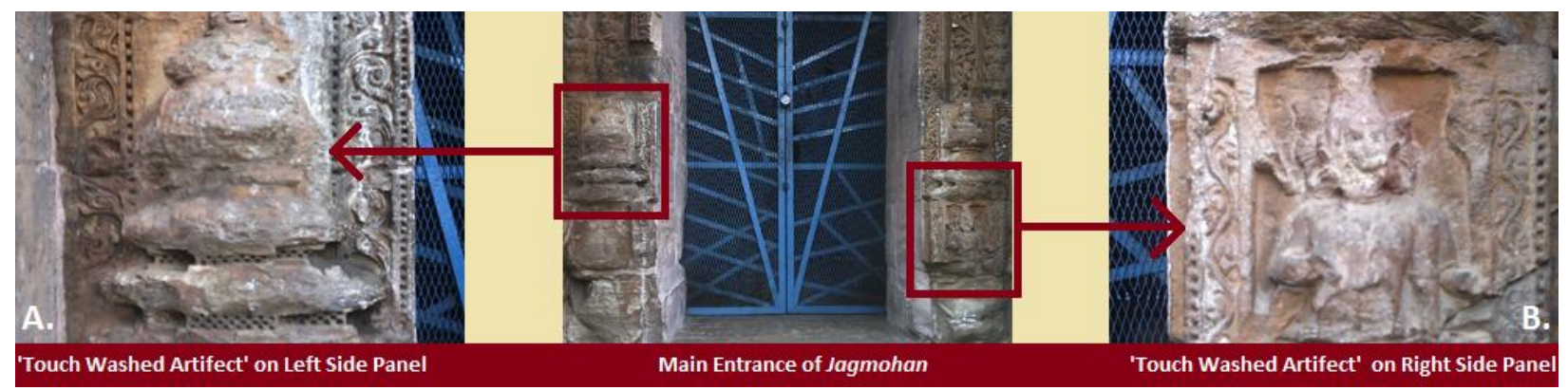

Image-15: Touch washed sculpted stone forms at the main entrance side-panels of Jagmohan in Chitrakarini Temple: (A.) Left Side Panel, (B.) Right Side Panel (Photography and Illustration by author)

This had been observed that the major damages had been occurred in two parts of human-similar idol's face and leg parts. The leg part got completely damaged due to regular Charan-Sparsh ${ }^{58}$

\footnotetext{
${ }^{56}$ (Das, 2010)

${ }^{57}$ Sculptural damages occurred due to regular touch by the pool of devotees on a regular basis during their holy offerings. Such effects had been observed on easily approachable sculptures, installed in a high devotee traffic zone, alongside of the Chitrakarini Temple's Jagmohan entrance.

${ }^{58}$ (Bhalla, 2009, pp. G-8)
} 
practices by the pool of devotees; while, the face parts got damaged due to the regular offering Naived ${ }^{59}$, like- sweets and other edibles- through pouring them into the lips and mouth region of such stone idols; please refer image-15(B). Other sculpted stone artifacts over the main entrance of this temple's Jagmohan was also found touch-washed, due to regular holistic touch by devotees, please refer left panel artifact, as displayed in image-15(A). In Hinduism, touching the deity's idol is a common and regular practice, which is responsible for these sculptural damages. Here this researcher wishes to mention that idol-touch practices should be avoided by the pool of devotees to preserve the sculpted-glory of any idol; as after all any human creation may get its physical shape using a material; and every material available over this earth has only a certain life-time, and is equally applicable for any stone structure as well.

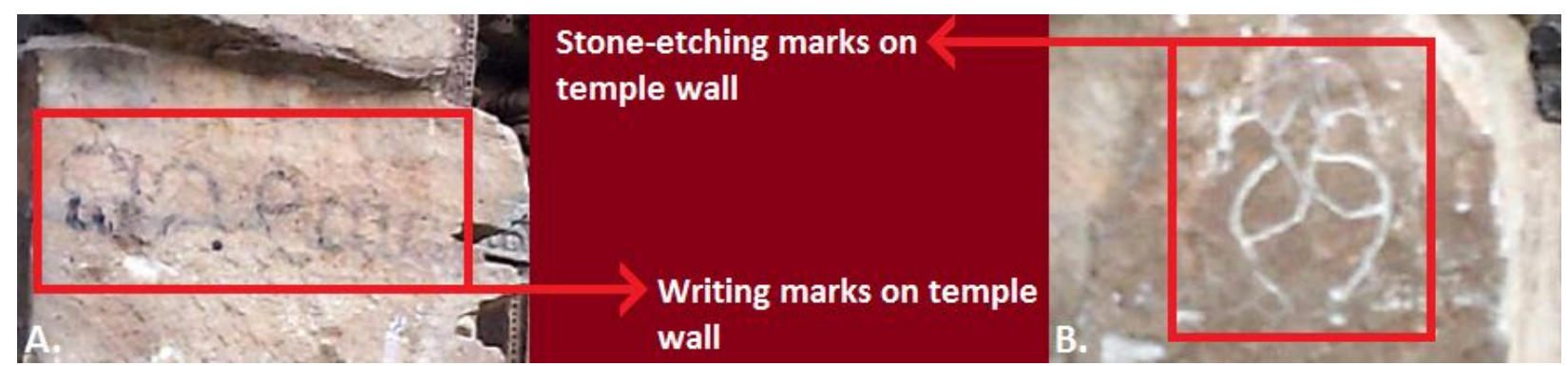

Image-16: (A.) Wall writing, (B.) Etching marks; over stone panels of Chitrakarini Temple (Photography and Illustration by author)

There were few writing and etching marks had also been identified over the wall panels of this temple, please refer image-16(A\&B). This should be avoided, as these are harmful in the direction to conserve this monument and its structural life ${ }^{60}$.

\subsection{Executed Amenity Enhancements Initiatives: A Study}

To extend the quality of basic utility needs, different technology driven systems had been installed in recent years within the Chitrakarini temple premises; among which importantly two classes of such systems had been found installed within the temple premises: (1.) Electricity based night lightning system installations, and (2.) Water supply system installations etc. However, such executions enhanced the quality of public utility facilities within temple premises; but as such installations were incorporated directly over the stone structures of this $13^{\text {th }}$ century old monument ${ }^{61}$, were found responsible to reduce the 'material-life' of this centuries old stone structure- which was found already suffering with serious stone decays and damages- due to the local nature caused atmospheric and other conditions. Further, this researcher had also observed lack in periodically required, post-installation maintenance. An example could be referred through image- $17(C)$; where an electric pole, found leaning over the boundary wall of this temple and was about to damage this permanent structure- if not been adjusted on a priority basis. Some of the other findings has also been referred in images-18, 19, 20 etc. further.

\footnotetext{
59 (Sanatan Sanstha, 2014)

60 (Hay, Scratching the Surface)

${ }^{61}$ (Richards, April 2010)
} 


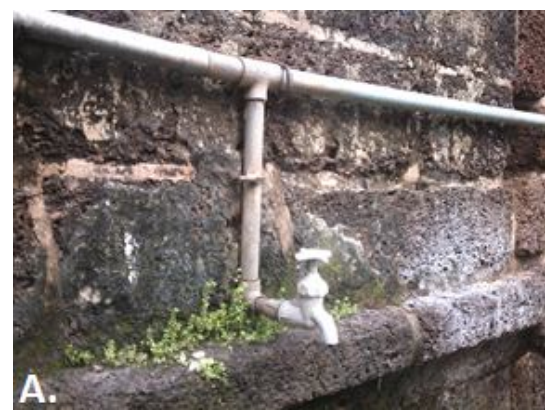

Image-17: Amenity
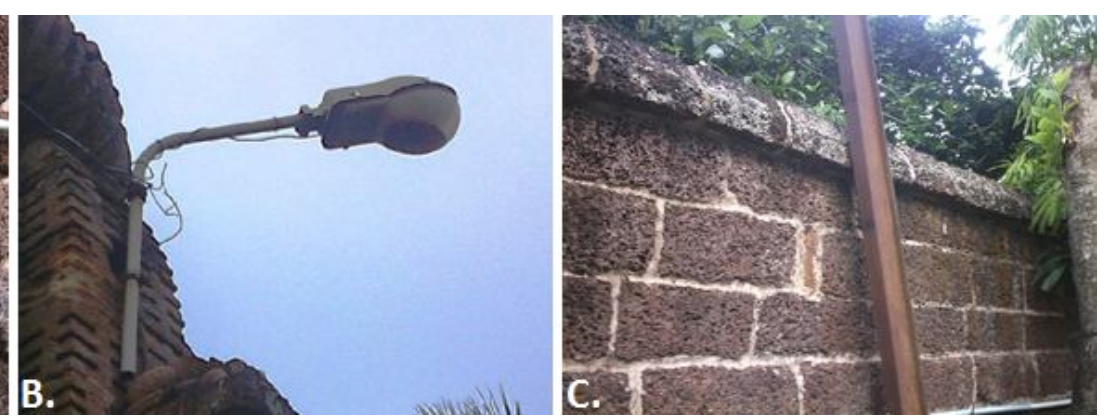

(Photography by author)

\subsubsection{Installation of Water Supply System}

Role of the fresh water supply had always been in prime importance at any religious premise across the religions ${ }^{62}$, to support its daily socio-cultural needs. Over the eastern wall of this monumental premise, there is Poly Vinyl Chloride ${ }^{63}$ based water supply system had been installed as displayed in image-17(A), with wrought iron made fixtures. These fixtures, as shown in image$18(C)$ were directly installed over this stone wall by penetrating its surface- this may offer cracks, groves etc. in such wall panels- when these non-coated iron fixtures get rusted ${ }^{64}$ and produce different oxidized residues while gradually exposed with atmospheric oxygen and moisture, which results volume expansion in oxidized iron; but as stone and cement can't expend as much, so getting cracks- and this way the entire wall structures may receive negative impact. The mark of an improperly execute plumbing system repair could be referred through image-18(R); where the stone block had been removed, while unclamping the old fixture.

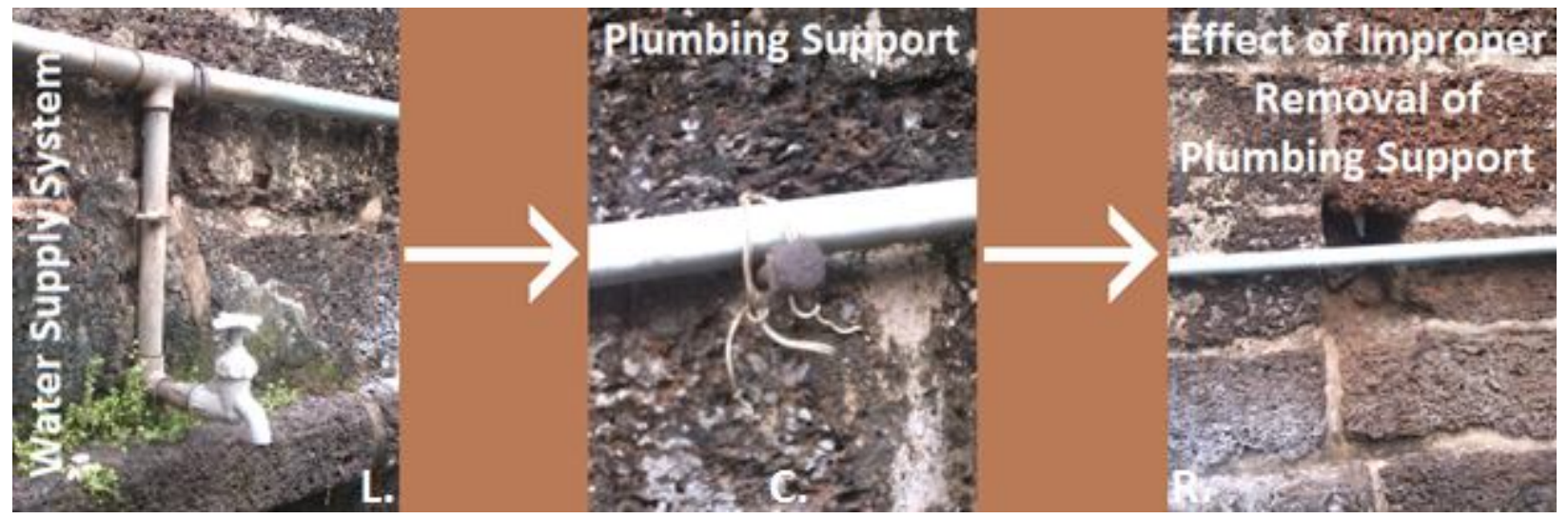

Image-18: A damage caused by the improper maintenance of water supply system on Chitrakarini Temple premise wall (Photography \& Illustration by author)

\subsubsection{Temple Electrification}

These days, electrification is considered as one of the basic requirement for night vision among human settlements; but when such electrification implemented directly over the wall panels of an around 900 year's old monument itself causing threats over its structural strength. In Chitrakarini Temple premises, majority of the electrification works had been found incorporated through

\footnotetext{
${ }^{62}$ (Water Policy International Ltd., 2000-2001)

${ }^{63}$ (HALLO-III, 2017)

${ }^{64}$ (Lancashire, 2001-2008)
} 
direct placements of iron nails and clamps, even this researcher had observed different holes with chiseling marks over this temple complex wall panels. Use of the external side pales found advisable for such electrification works, to preserve this temple for further generations.
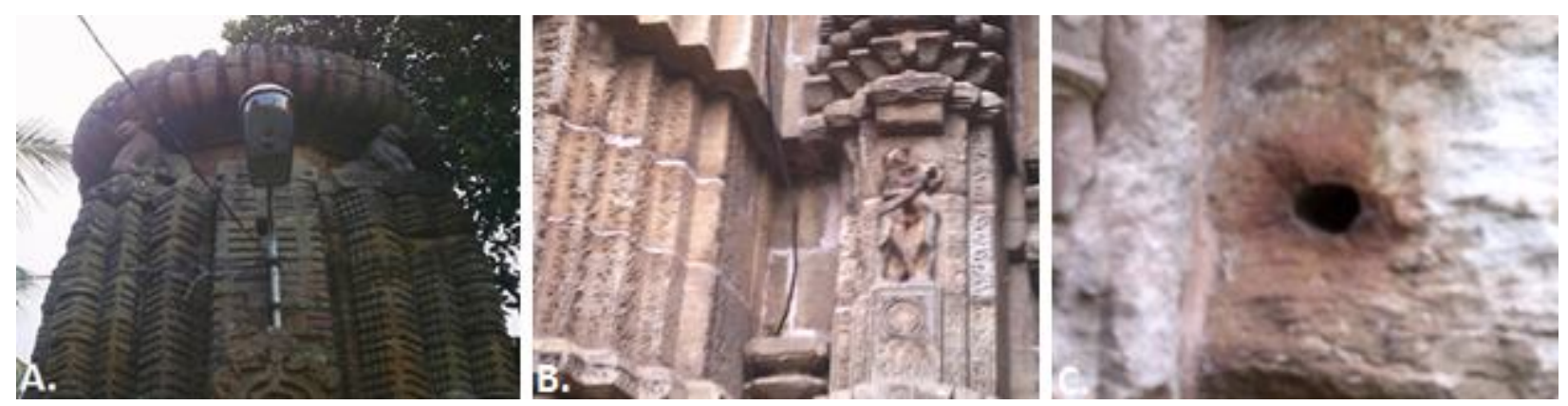

Image-19: Electrification in Chitrakarini Temple (A.) A lightning system- directly installed over the Temple panel, (B.) A functional electric wire- hanging along with the temple's external wall, (C.) An electrification purpose hole over the temple panel (Photography by author)

\section{Chitrakarini Temple's Revival Initiatives}

The Chitrakarini Temple is an Archeological Survey of India ${ }^{65}$ protected site, which is displayed in three different signage boards installed within this premise- along with different trilingual instructional descriptions, i.e. in regional language- Odiya, National language- Hindi, and International language-English etc. However there is no any signage found here, which may display the historical and other temple specific socio-cultural importance or similar information to the public. A bilingual temple-name-identification signage was placed by the Tourism Department of Odisha State Government ${ }^{66}$, in front of this temple; please refer image-2o(A) for this signage. However, being the subject to protect and conserve Chitrakarini Temple, such signage had great importance to identify this monument.

\subsection{Open Access Temple Documentation}

In the direction of authentic or official documentations about Chitrakarini Temple, a set of documents had been identified by this researcher. Some of them were:

- A photograph of this temple, clicked by William Henry Cornish in 1892 which was published by the British Library titled: General view of the Chitrakarini Temple, Bhubaneshwar- as an authentic library-document ${ }^{67}$.

- The review report, edited by the Director General of the Archeological Survey of India, published in 1973 could consider as another reference document ${ }^{68}$ about the Chitrakarini Temple.

- An official documentation about basic temple-information about Chitrakarini Temple. This documentation had been done by the Indira Gandhi National Centre for the Arts ${ }^{69}$ of New Delhi, bearing document number-OR/KDA/BSR-39.

\footnotetext{
${ }^{65}$ (Archaeological Survey of India, Government of India, 2011)

${ }^{66}$ (Department of Tourism, Government of Odisha)

67 (Cornish, General view of the Chitrakarini Temple, Bhubaneshwar, 1892)

68 (Archeological Survey of India, Government of India, 1973, pp. 35-37, 66, 77, 111-114, 123, 127, 133)

69 (INDIRA GANDHI NATIONAL CENTRE FOR THE ARTS)
} 
- An Office Order number 21/2009 issued by the Commissioner of Police, Bhubaneswar in 2009- and identifies Chitrakarini Temple as one of the local police-protected site. In this document, one may refer the name of Chitrakarini Temple under its annexure-A, at serial number-o $8^{70}$.

These documents could be considered as few available authentic or officially published identification documents, published through different authentic sources. Among other documentation, the video titled: Chitrakarini Temple-Bhubaneswar ${ }^{71}$, could also be referred for this temple's existing sculptural and structural status these days.
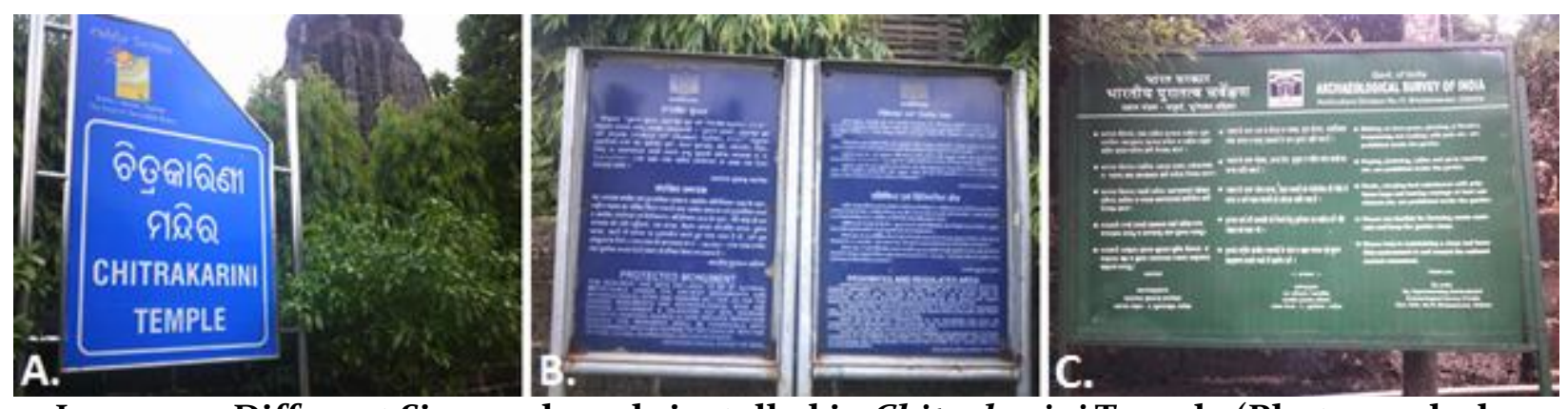

Image-2o: Different Signage boards installed in Chitrakarini Temple (Photographs by author)

During this field visit, a number of four different permanently installed documents had been found in the form of publically displayed signage. All of such signage were self-explanatory, neatly printed and clearly visible for the audience and could be broadly displayed in two categories:

\subsubsection{Personalized Signage:}

A bilingual (Odiya and English), Sky Blue colored signage, installed by the Odisha Tourism Department of the State Government of Odisha, outside the main entrance of this temple premise. This signage was displaying name of this temple, as: "Chitrakarini Temple"; and so could be categorized as a personalized signage. Please refer image-2o(A).

\subsubsection{Generic Signage:}

As remaining three signage boards were nowhere mentioning the name of "Chitrakarini Temple" in their set of literature, so could be categorized as the Generic Signage- which carrying set of information having equally important for all of the similar protected monumental sites wherever Indian law could be extended in force. All of these trilingual boards were installed by the Archeological Survey of India and carries different statutory information and instructions as:

\subsubsection{Protected Monument Signage:}

This Navy Blue colored signage (image-2o(B): Left) informs that this temple had been announced as a Monument Of National Importance, under the provisions of Ancient Monuments And Archaeological Sites And Remains Act'1958 $8^{72}$. Further this board also explains about different conservational protective provisions defined under the Ancient Monuments And Archaeological

\footnotetext{
70 (B.K. Sharma, Commissioner of Police, Bhubaneswar-Cuttack, 2009)

71 (San, 2015)

72 (Ministry of Law and Justice, Government of India, 1958, pp. 01-24)
} 
Sites And Remains (Amendment and Validation) Act'2010 ${ }^{73}$, disregarding this act may considered as a punishable offence for audience. Purpose of this signage was understood by this researcher as, to protect the temple structure and all parts of this premise.

\subsubsection{Prohibited and Regulated Area Signage:}

This Navy Blue colored signage (image-2o(B): Right) was displaying statutory instructions and limiting any type of construction or excavation around this temple's geographic periphery of 100 meters as prohibited area, and further 200 meters area as had been defined as 'regulated area'under provisions of Section-20(A\&B) of the Ancient Monuments And Archaeological Sites And Remains (Amendment and Validation) Act'2010. Disregarding such provisions had been identified considerable as a punishable offence under Section-3o(A\&B), of the same act. Purpose of this signage was understood by this researcher as, to offer an spacious and welcoming surrounding around this temple.

\subsubsection{Prohibited and Regulated Area Signage:}

This Green colored signage board was found installed within the temple premise, near the main entrance by the Horticulture Division-IV, Bhubaneswar of the Archeological Survey of India. This board was displaying different orders issued by the Deputy Superintending Horticulturist. Purpose of this signage was understood by this researcher as, to keep and maintain a green, clean and dignified environment around this temple's premise, refer image-2o(C).

\subsection{Existing Condition of Chitrakarini Temple's Restoration: A Study}

As per the findings, existing condition of architectural structures, sculptures and artifacts of the Chitrakarini Temple could be considered as a poorly damaged monument. So, as an appreciable initiative, re-cementing of the stone-cracks over the wall panels had been done. The repair marks of intensive conservational repair can be easily observed over the wall panels of the Chitrakarini Temple all around. In the direction of preserving this $13^{\text {th }}$ century built monument, which was found suffering from its multifold detreating conditions these days- itself was a challenging task. This challenging task had been incorporated using highly skillful hands of the monument conservators, which was commendable in itself.
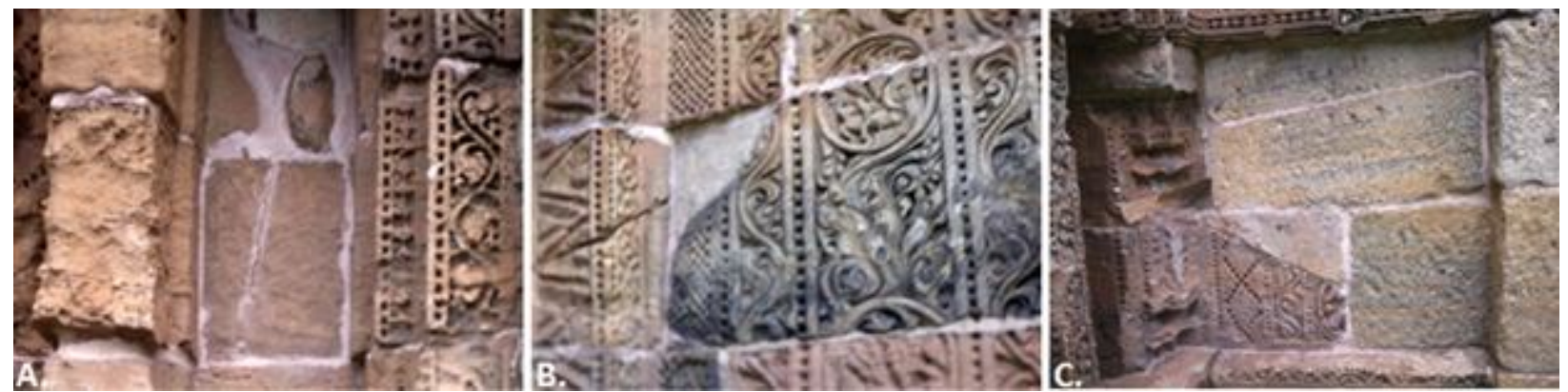

Image-21: Restored two-dimensional structures and murals: (A.) A cement filled, poorly damaged wall crack, (B.) A restored two-dimensional mural slabs with re-cemented joints, (C.) A poorly damaged originally sculpted wall panel restored using non-sculpted sand stone blocks- to protect this panel's strength (Photographs by author)

\footnotetext{
73 (PRS Legislative Research, 2010, pp. 01-17)
} 
However, as per the received findings received through this field visit, researcher was only able to identify repair works executed over the joints of two-dimensional surfaces of this temple's stone panels. Researcher was unable to identify any three-dimensional sculpture, which was repaired to retrieve its near-original sculptural form, within their 'own three-dimensional respective visual spaces'. None of the partially or completely damaged three-dimensional sculptures had been identified restored in such a manner, so that they may able to re-achieve their 'own form of identity(s)', as they might deserve.
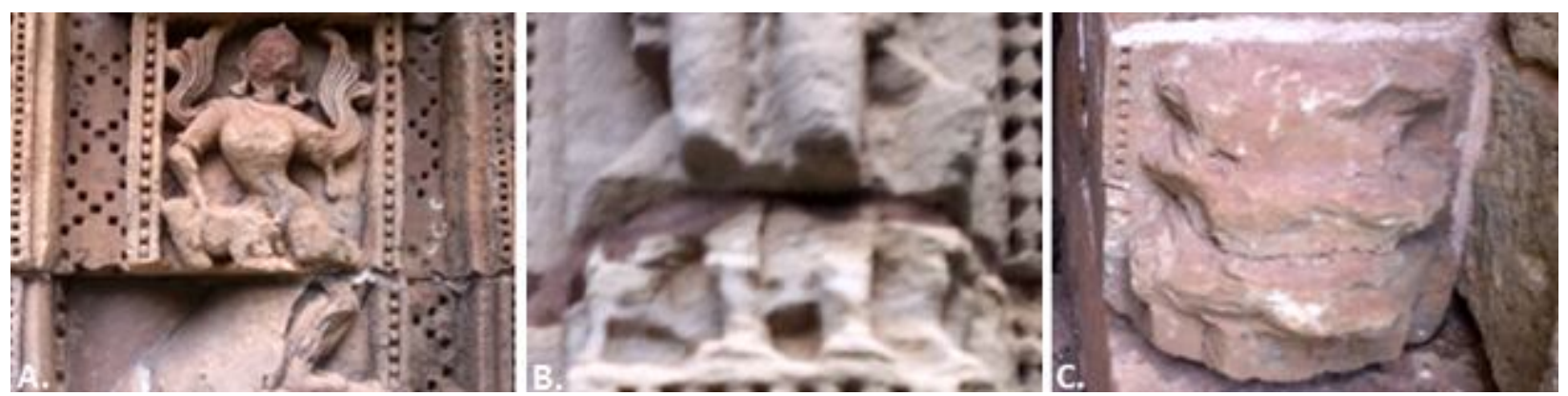

Image-22: Existing conditions of three-dimensional sculptures: (A.) A sculpture with completely lost its lower half section and damaged face, (B.) A poorly damaged sculpted section, where cement had been applied to cover the upper surface of stone joints, while the three dimensional sculptural form is untreated, (C.) A completely lost sculpture remain- in completely unidentifiable status (Photographs by author)

So, however this research appreciates the existing condition of restoration, but also criticizing this segment of ignorance, which was also supposed to be explored by the team of restorers. And so, this temple was still found in the need of three-dimensional sculptural restoration, and allowing sufficient space for further improvements, to re-achieve its previous-similar sculptural glory.
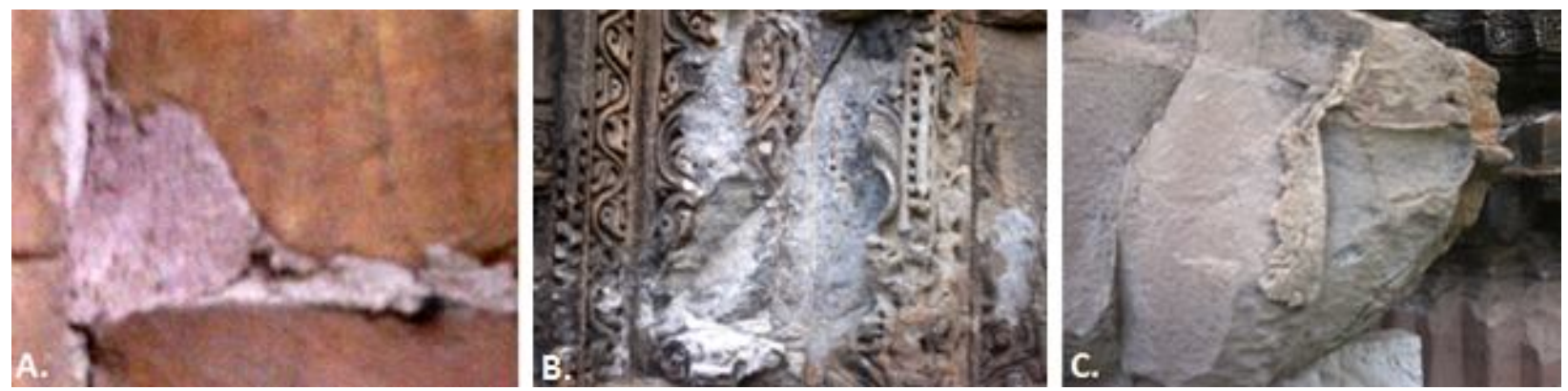

Image-23: (A.) View of a post application un-evened cement decomposition, (B.) A wall with artifacts get uncleaned by the excessive use of restoration material, (C.) View of a used cementing material mass, which was unable to hold its cemented extension

(Photographs by author)

Even, there were several examples had been identified, where cementing materials had not been cleaned up by the team of restorers, and now causing untidy visual appearance; please refer image-23(A)- this should be evened, using a piece of fabric- while the cementing material was in pouring condition. Few other sections of this temple's wall panels had been found extremely dirty, due to the improper spread of restoration materials and cracks were only partially treated; please refer image-23(B). This researcher was shocked to found a section of wall panel, where the used restoration cement was spread massively; and self-explaining that the used cement was unable to 
hold the cemented panel, and so dropped down the attachment. This might be resulted due to, either- (a.) weight of the attached stone segment was excessive, and merely applying cement was insufficient to restore and additional external reinforcement support was required along with the cement; or, (b.) applied cement's strength quality was lower than the restorer's estimation; please refer image-23(C). However this researcher cannot deny that, factors discussed under section-10.3, may also be responsible for such issue; however no any mark of chiseling or hammering had been traced over such remain of the blowout surface with 'used cement'.

\subsection{Temple Garden}

The premise of Chitrakarini Temple was full of greeneries and fragrances of carefully planted flowers all around; and ably provides an excellent visual appearance. Every piece of land, lies within the temple's premise may be considered as a carefully designed and crafted garden. The gardening work had been executed by the Horticulture Division-IV, Bhubaneswar of the Archeological Survey of India.
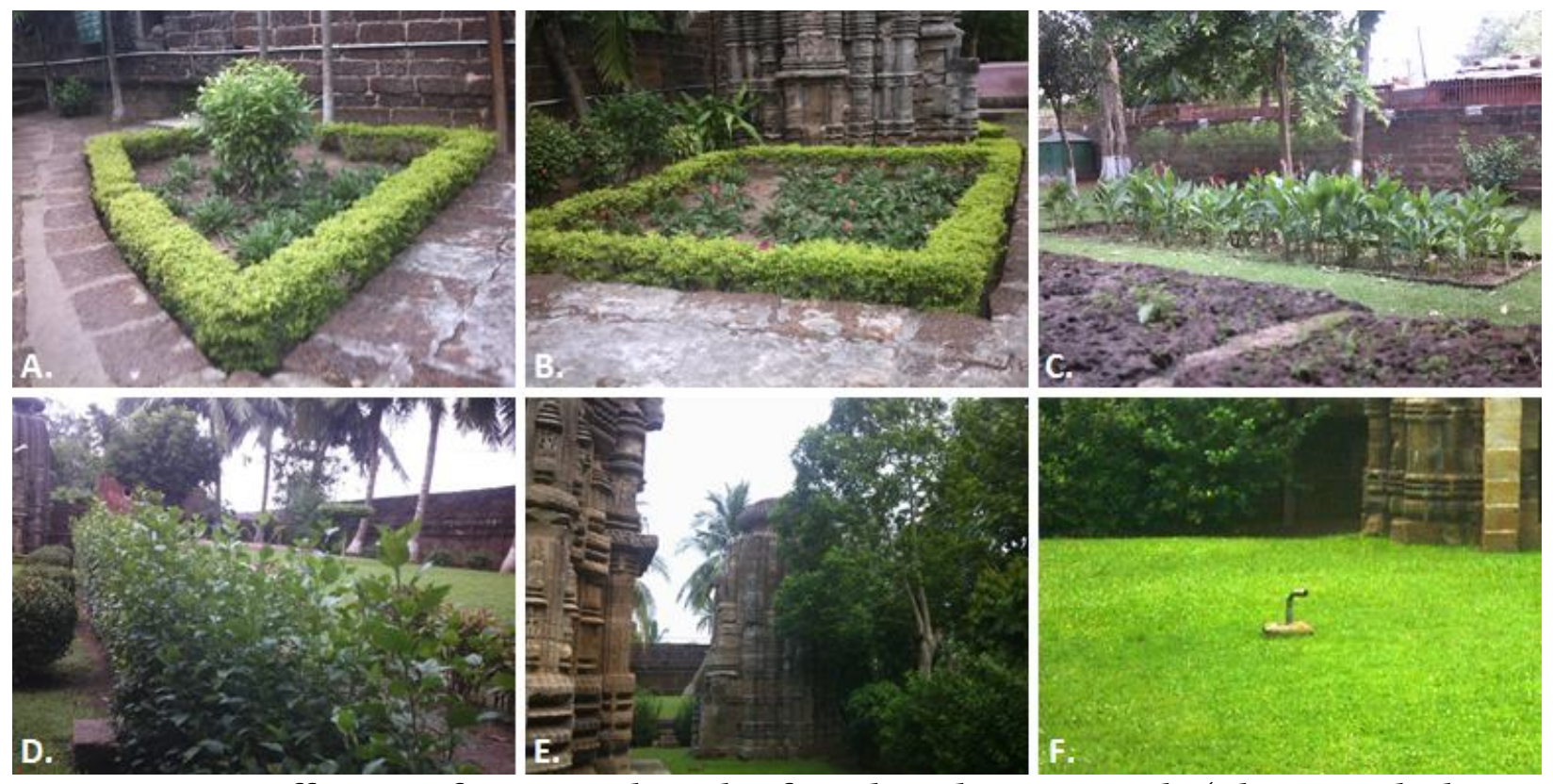

Image-24: Different information boards of in Chitrakarini Temple (Photographs by author)

This researcher appreciates the rigorous efforts made by the Horticulture Division-IV, Bhubaneswar of the Archeological Survey of India, in the direction to restore this temple's surrounding ambience. During his field visit, this researcher came across with a couple of findings on an actual basis, where government orders and above efforts had been ignored ${ }^{74}$ at local level. Here this has been found important to mention, that the purpose of highlighting such findings by this researcher is purely holistic towards attracting the Local Community Supports ${ }^{75}$ - as this temple and its premise carries their native socio-cultural and religious values since last 900 years and so they cannot ignore their responsibilities to maintain their own surroundings clean and presentable to the remaining world. So, if government agencies are initiating some welcoming

\footnotetext{
74 (Dwyer, 2011)

${ }^{75}$ (School of Architecture \& Design, The University of Kansas, 2017)
} 
steps, they should at least support such initiatives at local level, by respecting basic guidelines, as displayed through signage instructions in image-2o(C).

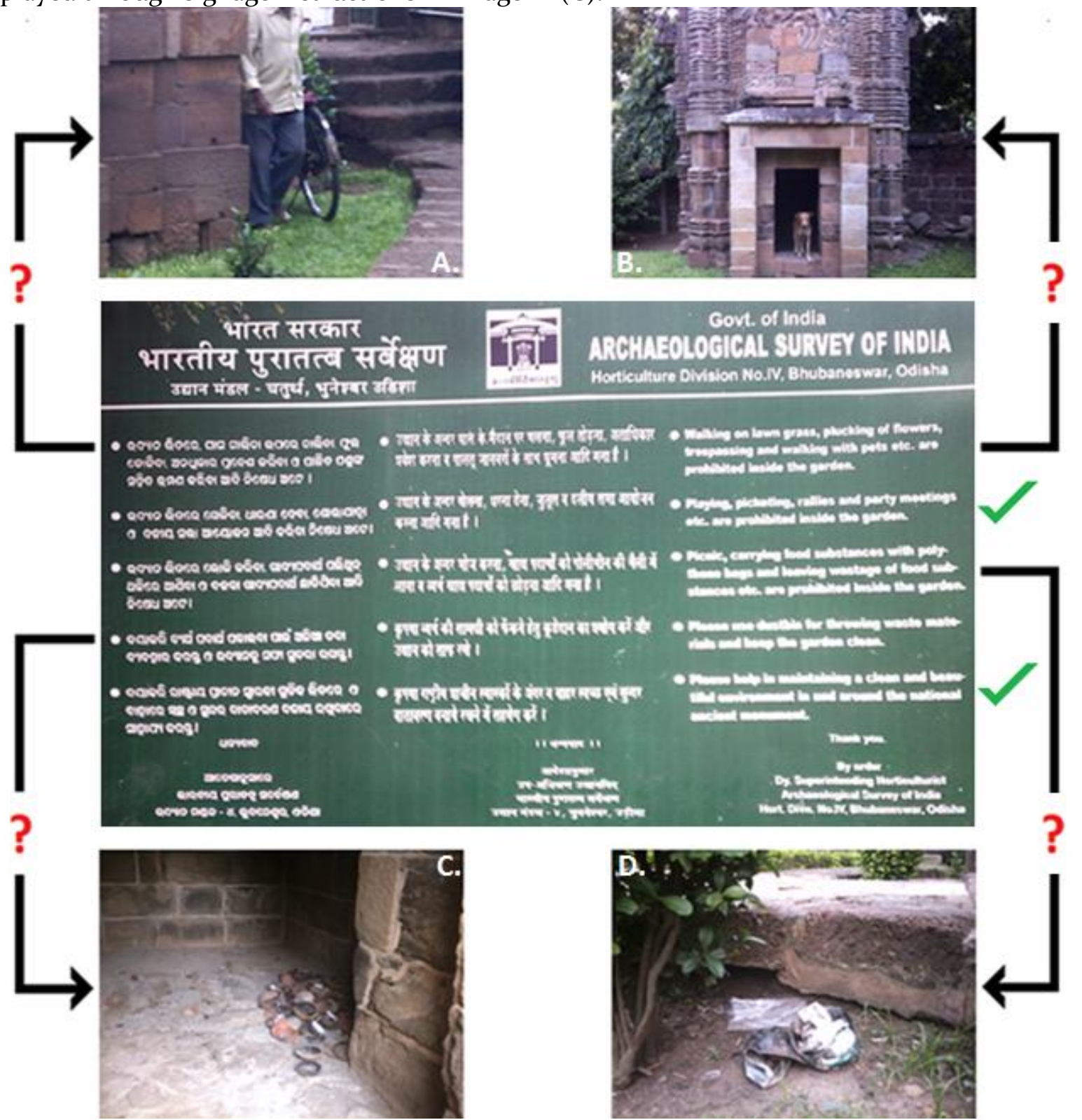

Image-25: A few cases of ignorance at local level towards government orders displayed in signage installation in Chitrakarini Temple premises: (A.) A local visitor walking on garden grass along with his bicycle, (B.) A street dog residing in a peripheral temple (without any existing idol) as her home- became stand with aggression at temple's dooras disturbed by the unexpected presence of this researcher, $(C$.) Next peripheral temple (also without any existing idol)- used as the junk yard for the post worshipped-used oil lamps, (D.) A bunch of used local food packaging left out (oil washed newspapers and polyethylene bags) (Photographs and illustration by author)

But local ignorance had been identified, by ignoring the fact that due to Chitrakarini Temple's socio-cultural and architectural excellence, this temple had been declared as a 'Monument Of National Importance', under The Ancient Monuments And Archaeological Sites And Remains 
Act'1958- by Government of India, please refer image-20(B); and so this is important to respect government's holistic decision and contribute at their own level.

Findings regarding some of the examples at local level ignorance could be referred through the illustration displayed in image-25, along with the orders issued by the Deputy Superintending Horticulturist of Horticulture Division-IV Bhubaneswar, Archeological Survey of India. This signage was permanently installed within the temple premise near its entrance, so that instructions could be easily visible; and written script was also clearly readable and understandable in Odiya, Hindi and English languages- so that any visitor may read, understand and follow such instructions.

The role of local communities and residents may considerably contribute towards the monumental conservation, premises cleanliness, and local holistically support different government initiatives, to make their own habitat a batter place to live for themselves, and maintain the socio-cultural and religious legacy for further generations. So, local residents could be made aware, trained, and equipped with local monument management, as their local social responsibility ${ }^{76}$. This might also contribute towards enhancing the traffic of tourists and help to enhance revenue growth for local government ${ }^{77}$.

In image-25, for ease to understand, there were two types of illustrative symbols had been used as: " $\checkmark$ " and "?"; where " $\checkmark$ "- represents that nothing identified against the subjected order-statement; while“?"- represents the contraindicative findings against this government order, along with evidences received, on an actual basis, form the Chitrakarini Temple premises.
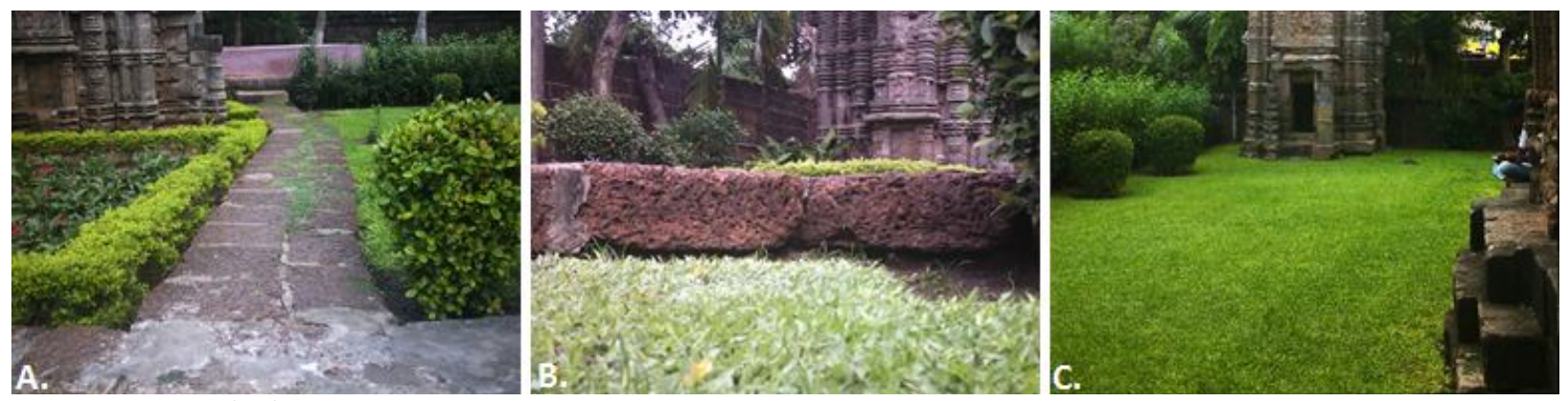

Image-26: (A.) Internal Footpath connecting main temple with two other front located peripheral temples and main entrance of the temple premise, (B.) Clay erosion below the internal footpath, (C.) Remaining two peripheral temples were not found connected with any internal footpath (Photographs by author)

\subsection{Internal Footpath}

This temple carries internal footpath to approach the main deity's temple from the common entrance of the Chitrakarini Temples premise. Further connecting two front side situated peripheral temples with worshipping deities and the Tulsi Chaura ${ }^{78}$. This footpath was built using laterite sandstone; however remaining two peripheral temples- situated in back of the main

\footnotetext{
${ }^{76}$ (Gyan P. Nyaupane, 2010)

77 (Sirisrisak, 2009)

78 (GhenNet, 2000)
} 
temple, were found unconnected with any footpath. Both of these unconnected peripheral temples were found without any currently existing idols of deity. However, these two peripheral temple's architectural, sculptural and other creative expressions were found comparable with the remaining two front facing as well footpath connected peripheral temples; and equally appealing for any visitor of this premise.

So, as per the findings, both of these peripheral temples had also been connected through extending the footpath, to allow visitors to approach these temples having comparable sculptural importance. This way, a visitor could be self-motivate to walk only through the defined footpathwithout damaging well-crafted grass-mat of this garden.

\section{Significance of Chitrakarini Temple in contemporary era \\ 11.1. Paintress of Life: Mother}

In contemporary context, the term: "Paintress" reflects- the "Paintress of Life" and recognizes the vital role of a mother in their child's grooming process! During this field visit, a sizable number of sculptures had been identified, which portrayed different forms of a mother's responsibilities, holistically carried by her on a daily basis- in day to day life. This set of sculptural collection from the wall panels of Chitrakarini Temple, reflects "Paintress Of Life: As Mother". Please refer image27.

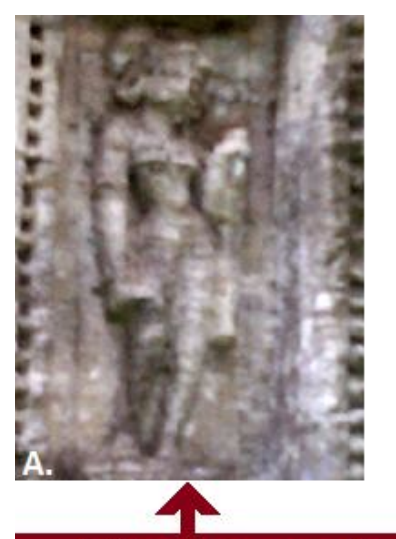

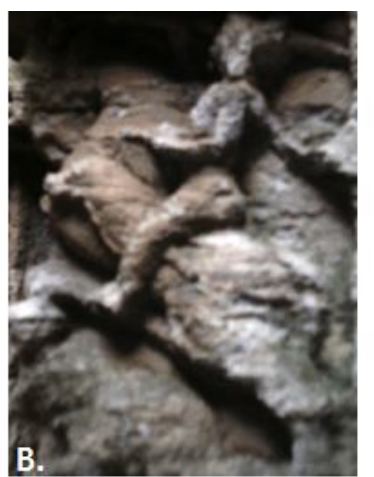

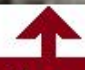

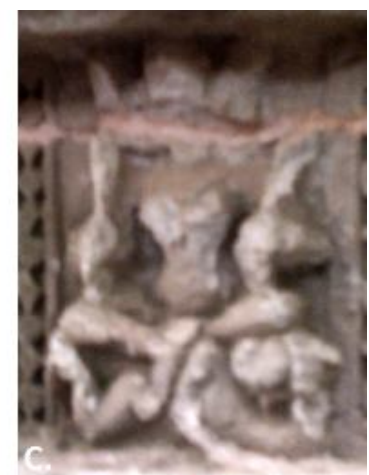

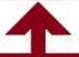

Different forms of a mother: Representing mother as the first feeder, companion, caretaker, teacher etc.- who overall paints and safeguards her child's life
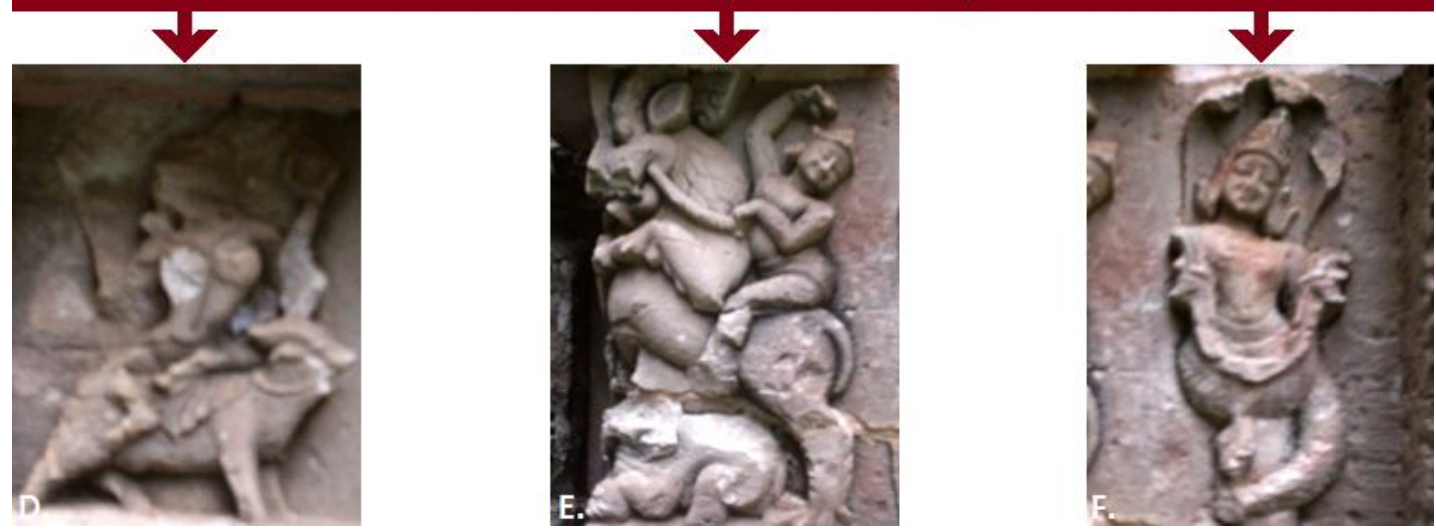

Image-27: Different forms of responsibilities, performed by mothers on a daily basis towards the care, nourishment and protection for her children (Illustration and Photography by author) 
However this temple's sculptures found getting faded over the wheel of time, but were still able to express a lot, through their sculptural expressions. Through the sculpture, displayed in image27(A), a mother had been represented as the first accompany and teacher, who keeps her eyes open, alert and focused over the overall grooming of her child. Through the sculpture, displayed in image-27(B), mother had been represented as quick attendant- who quickly fulfils requirements raised by her kid like. In this sculpture, quickness of a mother had been iconized by horse. Through the sculpture, displayed in image-27(C), mother was represented as an alert defender from any threat(s) against her child. Through the image-27(D), mother had been represented as a feeder and caregiver for life, her child-feeding concerns had been iconized by the sheep- which provides milk and wool- and symbolizes protection from the hunger and weather generated threats for human sustenance. Sculpture displayed in image-27(E), represents mother as a fighter and killer of all negative impact causing thought process- during her child's psychological grooming; in this sculpture her killer attitude was iconized through a lion. In image-27(F), displayed sculpture mother represents mother as the first doctor, who cares her child and make her away from all health threatening evils- with always dancing pleasant smile over her face.
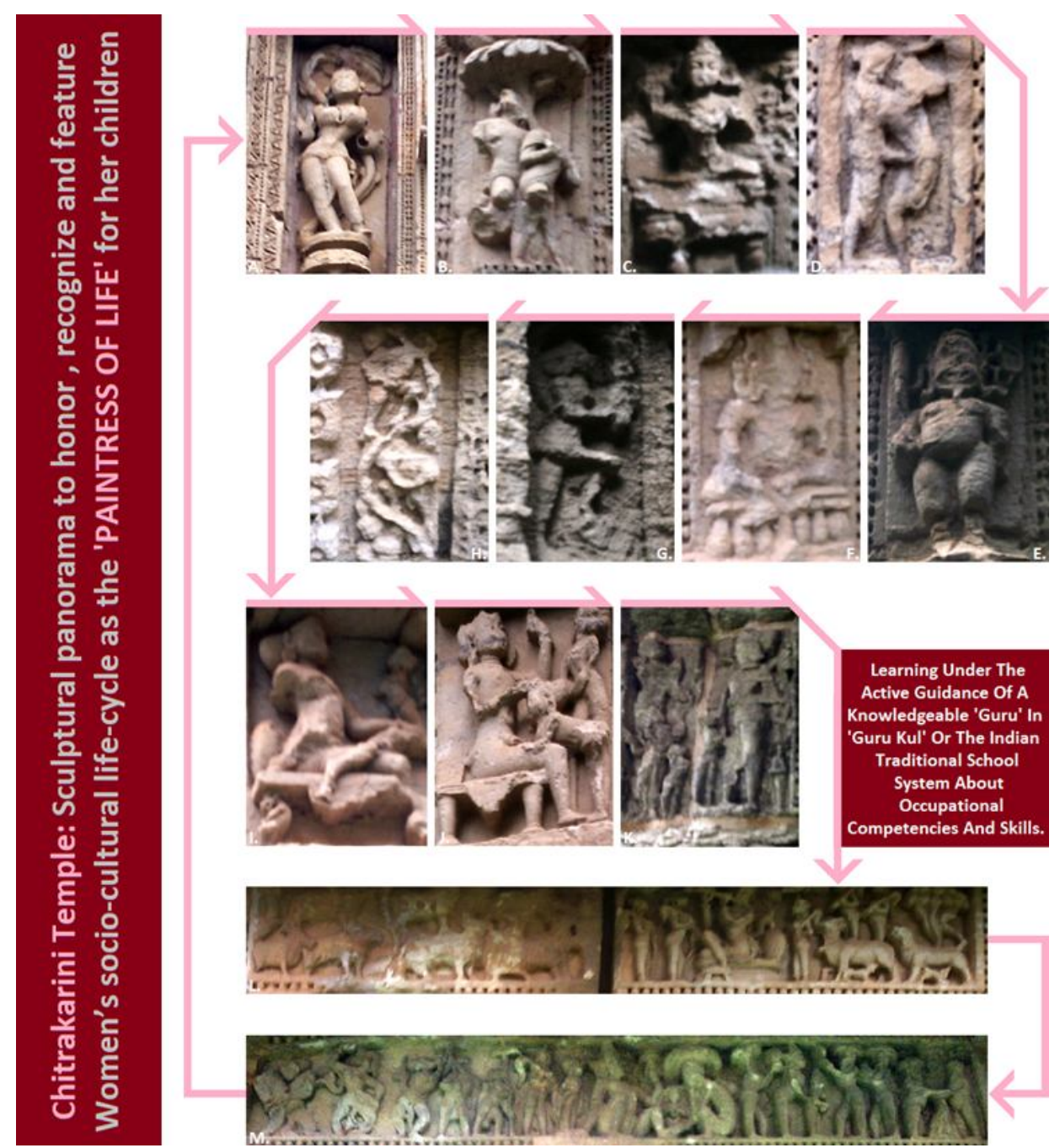

Image-28: (A.) The self-explaining life-cycle panorama of a woman as the 'Chitrakarini', or 'Paintress of Life' (Illustration and Photography by author) 


\subsection{Paintress of Life: Human Settlement}

Carefully carved wall panels of Chitrakarini Temple were well-articulated canvas, which displays life cycle of an idle women and honors the power of feminine contributions, towards life-building over this planet. Through the sculptural panorama of temple, the role of a woman had been displayed through multiple phases. This set of sculptural collection from the wall panels of Chitrakarini Temple, reflects "Paintress of Life: For Human Settlement". Please refer image-28.

\subsection{Paintress of Life: Creative Professions and Academia}

During the equivalent English terminology search, for the term, "Chitrakarini", this researcher found "Paintress", in Collins Dictionary, where this word was available since 1797; and its wordmeaning was explained as- "A Female Painter"79. Further, as per the Wiktionary ${ }^{80}$, etymology of this term is 'Painter + Ess'. The term Paintress is a noun and its plural form is Paintresses. However, this was quite painful experience for this researcher not to found any equivalent term for- "चित्रकारिणी", in any Sanskrit; or in any Hindi or in any Odiya online dictionary resources during his multiple search attempts. This word is derived from the term: "चित्र" or "Chitr". In contemporary context, this Sanskrit originated word represents different meanings as a motherterminology, out of which a few are- drawing, painting etc. and carries beauty, aesthetics, proportion, precision, imagination, planning etc. as its integrated elements. This term's extended applied forms could be identified today through- Painting, Drawing, Sculptures, Craft Design, Architecture, Interior Design, Exhibition Design, Social Design, Public Space Design, Civil Engineering, Home Science, Creative Writing, Graphics \& Animation Design etc. and are being recognized as independent professional streams.

Further, if go along the lateral association of "Chitrakarini" or "Female Painter" or "Paintress" with present context- when different forms of 'creative expressions' had received recognition as independent subject of studies in different educational and professional setups throughout the world, and a large pool of universities, institutions and colleges are teaching, training and skilling students through different set of academic programs, like- Bachelors, Masters, MPhil, PhD etc., with an comprehensive list of creative sector focused specializations, like- Craft Design, Architecture, Interior Design, Exhibition Design, Social Design, Civil Engineering, Home Science, and a number of Fine Arts disciplines, like- Sculpture, Painting etc.; by following well-defined teaching pedagogies. In this context, the term- Chitrakarini, establishes its importance with this temple's nomenclature only; and could be referred as one of the first ever used term: 'Chitrakarini', which had been used to encompasses "Creative Sectors"- as across these sectorsbeauty, aesthetics, proportion, precision, imagination, planning etc. had always been placed at the center of learning and explorations- which could be efficiently compared with the active contributions by a woman towards turning her house into a beautiful home.

\subsection{Contemporary Impact of the Chitrakarini Temple in Modern Architecture}

In front of the Chitrakarini Temple, there was a house with beautiful cement-casted surface ornamentations. This is a property of Mr. Dhrubacharana Sahu. Construction of this house was concluded in 1951. House is an excellent example of contemporary architectural exploration, where the sculptural legacy of the Chitrakarini Temple had been skillfully fused with the roman

\footnotetext{
79 (Collins English Dictionary, 1797)

${ }^{80}$ (Wiktionary, 2017)
} 
expressions (Please refer, India received independence in August, 1947 from the British rule ${ }^{81}$ which was merely 04 years before concluding this building's construction)- so, the effects of the then socio-political impacts could be seen through artifacts of this building.

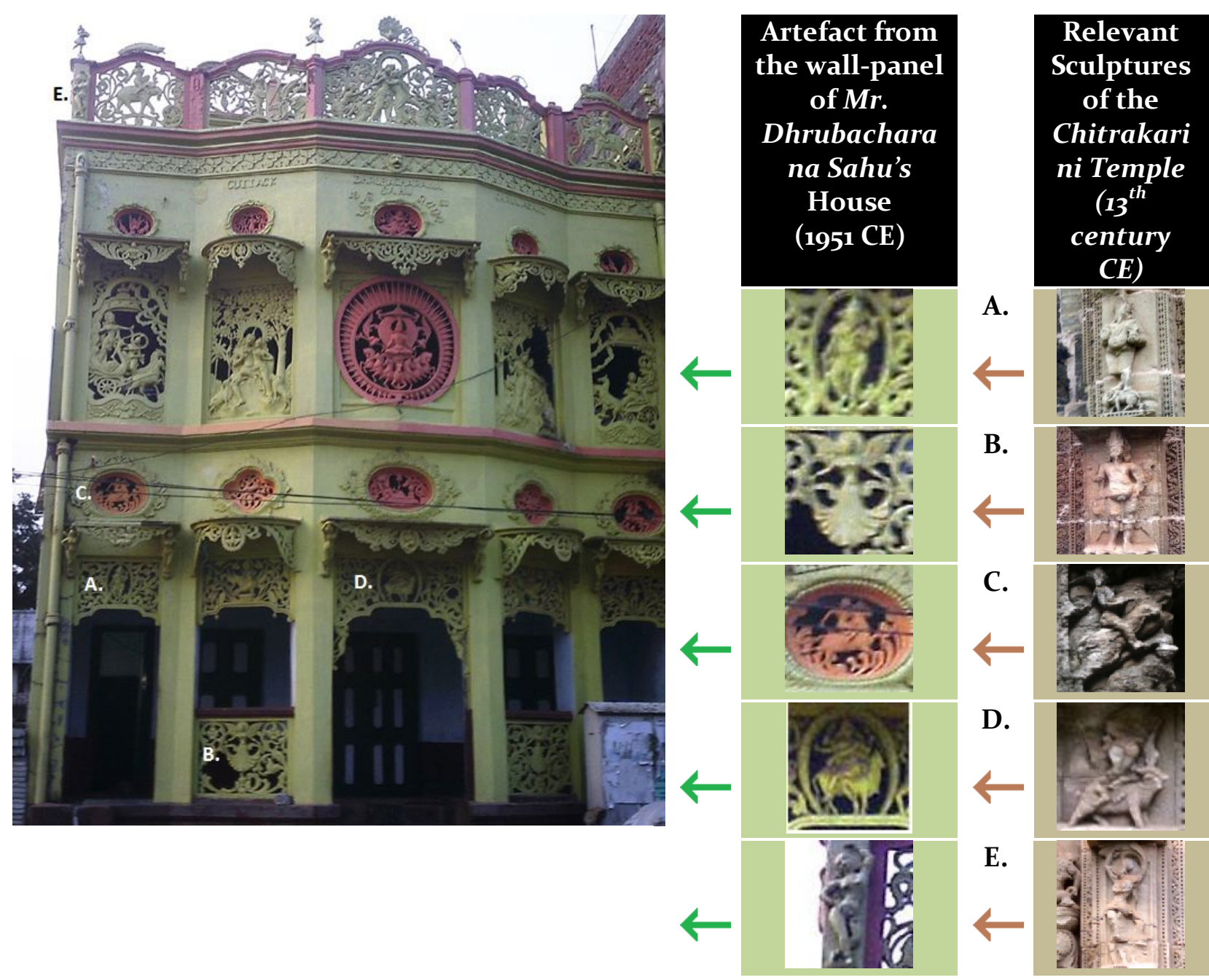

Image-29: Different sculptures of the Chitrakarini Temple had been used in a neighboring house, built in 1951 by Mr. Dhrubacharana Sahu in Old Town Area of Bhubaneswar. This house is sustaining today (during 2017-2018), and found under regular use by the family of its owner (Illustration and Photography by author)

The external surface of this building was made up of 'Portland Cement' ${ }^{82}$. Artifacts are primarily based over the Hindu Religion oriented different epics, as used in Chitrakarini Temple's wall panels. Majority of the forms of this building's ground floor were identified, either as the direct metaphor of a few sculptures of Chitrakarini Temple- please refer image- 29(A,D\&E); or were its near similar versions with the then influencing European stylization, please refer image- 29(B\&C). Further the first floor of this building surrounds different epics of the Lord Krishn ${ }^{8_{3}}$, as inscribed

\footnotetext{
81 (Guardian News and Media Limited, 2017)

82 (Portland Cement Association, 2017)

${ }^{83}$ (Encyclopædia Britannica, Inc., 2017)
} 
in the holy Hindu book Mahabharat ${ }^{84}$. According to Hindu mythology, Lord Krishn was an incarnation of God Vishnu ${ }^{85}$; which relates the building with Vaishnavism, like the Chaitrakarini Temple. Artifacts of this floor highlights two forms of lord Krishn- first as the epic guru- while though delivered the Geetopdesh ${ }^{86}$ to his friend and follower Arjun ${ }^{87}$, before the Mahabharat $W a r^{88}$; and second as an epic lover, while sharing pleasant time with her sole-met Radha ${ }^{89}$.

\section{Conclusion}

Sculptural panorama of Chitrakarini Temple not only encompasses the human life, but also extends its dimensions to honor female's contributions across the pool of creatures who shares our biosphere equally. Even mythological forms had been honored to create and establish lifelinks between human being and different members of animal kingdom- in this temple sculptures. And establish the statement, that a mother is only a mother; and is regardless to limit her status by bounding her identity with any race or ethnicity. This perspective of Hindu philosophy is commendable in itself!

As understood, the central philosophy behind this temple was to honor feminine contributions towards the evolution, creation, management and maintenance of life cycles; and so, worships and honors her as the 'Paintress of Life'. Where being a 'Paintress of life' she acts as: an appeal of beauty- when she gets younger; a cheerful partner- she gets married; a responsible mother- when her child takes birth; the first teacher and caregiver- when her child first tries to understand their surroundings; as the guide- when her child grown younger and get ready to self-sustain further stages of their life, as displayed through illustrations of image-27 and 28. According to the local socio-cultural beliefs, today, Goddess Chitrakarini is recognized as a form of "Matridevi" or Mother Goddess by local devotee. As per local believes, this goddess blesses her followers with intellectual growth and encourages them to "beautify their overall family-life", using their constructive aptitude and attitude. Goddess Chitrakarini is still being worshipped today by the newly wedded Hindu Brides, with the belief to receive blessings of Goddess Chitrakarini, so that they may ably any successfully beautify their overall forthcoming family-life, and may establish herself- as a cheerful partner for her husband, a responsible mother for her forthcoming children and a responsible citizen for this planet. This way the Chitrakarini Temple establishes, that a women should not be treated as a second class citizen in any aspect ${ }^{90}$; they always has had their own and equal identity, which makes them equally important. So they should must be respected and honored $^{91}$ accordingly. So, this $13^{\text {th }}$ century built Hindu temple could be considered among the first known 'Feminine Power Expressionist Architectural and Sculptural Panorama'.

In contemporary context, Sanskrit originated word "Chitr" represents different meanings as a mother-terminology, out of which a few are- drawing, painting etc. and carries beauty, aesthetics, proportion, precision, imagination, planning etc. as its integrated elements. This term's extended applied forms could be identified today through- Painting, Drawing, Sculptures, Craft Design,

\footnotetext{
${ }^{84}$ (Anindita Basu/Ancient History Encyclopedia Limited, 2016)

85 (Patheos, 2013)

${ }^{86}$ (S.Malhotra, 2011)

${ }^{87}$ (Cristian Violatti/Ancient History Encyclopedia Limited, 2013)

${ }^{88}$ (Verma, 2014)

89 (The Bhaktivedanta Book Trust International, Inc., 2002-2015)

90 (Longjam Bedana, 2014)

${ }^{91}$ (RESPECT WOMEN, 2014)
} 
Architecture, Interior Design, Exhibition Design, Social Design, Public Space Design, Civil Engineering, Home Science, Graphics \& Animation Design along with a number of Fine Arts disciplines, like- Sculpture, Painting etc.; and are being recognized as independent professional streams. So, in this context, the term "Chitrakarini" is establishing its relevance with the contemporary era.

But these days Chitrakarini Temple is in requirement of the overall serious monumental revival. Otherwise this might be difficult to preserve this historical monument's glories for further generations. This will be an irreversible, irrevocable loss for the entire human settlement, feminist movements, and of course for the creative disciplines across the world.

\section{Acknowledgement}

Author is dedicating this research work to all women contributors as- (1.) Overall Life Sculptor (Mother): Mrs. Sudha Jha; Childhood Shapers (Grandmothers): Lt. Mrs. Taleshwari Devi Jha (Dadi'Ma) and Lt. Mrs. Sushila Choudhary (Nani'Ma); and my caring life-partner (Wife): Dr. Kabita Mishra. Without their active lifelong inputs, encouragements and enlightenment, this researcher could not be able to complete this research work. Further this researcher acknowledges and honor the endless contributions made by the entire race of women and female, who tirelessly, continuously contributing towards building this planet, as a place to live happily for the entire community of leaving beings. This project was self-funded, self-motivated, exploratory research work.

\section{References}

A.C.Pradhan. (2013). The New Capital at Bhubaneswar-Odisha Government. Retrieved July 05, 2017, from odisha.gov.in/e-magazine/Orissareview/2013/apr/engpdf/55-59.pdf

Amazon.com, Inc. (1996-2017). Andoer R1 1080P 15fps Full HD 24MP Digital Camera Cam Camcorder 3.o" Rotatable LCD Screen Anti-shake $4 X$ Digital Zoom Retractable Flashlight with UV Filter. Retrieved June 30, 2017, from https://www.amazon.com/Andoer-Camcorder-Anti-shake-RetractableFlashlight/dp/BoiN2JER5o

American Institute of Indian Studies. (1981). Kalādarśana: American Studies in the Art of India. (J. G. Williams, Ed.) India: Leiden E. J. Brill.

Anindita Basu/Ancient History Encyclopedia Limited. (2016, August 25). Mahabharata. Retrieved January 01, 2018, from https://www.ancient.eu/Mahabharata

Archaeological Survey of India, Government of India. (2011). About us. Retrieved October 18, 2017, from http://asi.nic.in/asi_aboutus.asp

Archeological Survey of India, Government of India. (1973). Indian Archeology 1956-66: A Review. (A. Ghosh, Editor, \& Naba Mudran Private Limited, Calcutta-4) Retrieved October 20, 2017, from http://asi.nic.in/nmma_reviews/Indian\%2oArchaeology\%201965-66\%20A\%2oReview.pdf

B.C.Punmia, A. K. (1984). A Text Book of Building Construction. New Delhi, India: Laxmi Publications Private Limited.

B.K. Sharma, Commissioner of Police, Bhubaneswar-Cuttack. (2009). COMMISSIONER'S ORDER NO.21/2009: Prevention of vandalism and encroachment of Archaeological Monuments/ Sites/ Remains etc. Retrieved October 24, 2017, from Bhubaneswar-Cuttack Police: http://bhubaneswarcuttackpolice.gov.in/pdf/co_no_21_o9.pdf

Balasubramanian, D. (2015, November 08). Science: Why save the rocks of the Deccan Plateau? Retrieved July 04, 2017, from The Hindu: http://www.thehindu.com/sci-tech/science/why-save-the-rocks-of-thedeccan-plateau/article7855580.ece

Bedi, P. (2013, November 03). Respect the goddess within every woman. The Times of India. India: Bennett, Coleman \& Co. Ltd. 
Behera, K. S. (2008). THE LINGGARĀJA TEMPLE OF BHUBANESWAR: ART AND CULTURAL LEGACY. New Delhi: Indira Gandhi National Centre for the Arts.

Bhalla, P. P. (2009). Hindu Rites, Rituals, Customs and Traditions: A to Z on the Hindu Way of Life. New Delhi, India: Pustak Mahal.

BIBHUTI BARIK, N. P. (2013, May 05). Craftsmen chisel city \& suburb into art hub-Boost for artists as entrepreneurship blends with creativity. The Telegraph, p. Unknown.

BP Agile. (2017, June). FPS SYSTEM TRANSPORTATION AND PROCESSING AGREEMENT: SECTION 2CONDITIONS OF CONTRACT. Retrieved July 05, 2017, from http://www.bp.com/content/dam/bpforties-pipeline/en/pdf/FPS\%2oStandard\%2oTPA\%2oSection\%202\%20(April\%202014\%20\%2oFinal)_1.pdf

Brown, R. L. (1991). Ganesh: studies of an Asian god. Cincinnati, Ohio, USA: Albany: State University of New York Press.

Centre for Cultural Resources and Training, Ministry of Culture, Government of India. (2017). Temple Architecture. Retrieved October 11, 2017, from http://ccrtindia.gov.in/templearchitecture.php

CG Gyaan Manthan. (2017, February 12). रस, एवं रस के प्रकार. Retrieved October 18, 2017, from http://cggyanmanthan.com/2017/02/12/रस-एवं-रस-के-प्रकार

Chitgopekar, D. N. (2011-2014). Ganesha: Lakshmi and Saraswati. Retrieved October 21, 2017, from The Ganesha Experience: http://theganeshaexperience.com/ganesha-lakshmi-and-saraswati

Collins English Dictionary. (1797). Definition of 'paintress'. Retrieved October 12, 2017, from https://www.collinsdictionary.com/dictionary/english/paintress

Cornish, W. H. (1892). General view of the Chitrakarini Temple, Bhubaneshwar. Retrieved July 04, 2017, from British Library: http://www.bl.uk/onlinegallery/onlineex/apac/photocoll/g/o19phoooooo10ozuoo2420oo.html

Cornish, W. H. (1892). General view of the Chitrakarini Temple, Bhubaneshwar. Retrieved October 20, 2017, from The British Library: http://www.bl.uk/onlinegallery/onlineex/apac/photocoll/g/o19phoooooo10o3uoo2420oo.html

Cornish, W. H. (1892). Papanasini Tank and temples to the north, Bhubaneshwar. Retrieved July 04, 2017, from British Library: http://www.bl.uk/onlinegallery/onlineex/apac/photocoll/p/o19phoooooo1003uoo3250oo.html

Cristian Violatti/Ancient History Encyclopedia Limited. (2013, September 15). Arjuna. Retrieved December 30, 2017, from https://www.ancient.eu/Arjuna

Culture Department, Government of Odisha. (2015, January 09). Temple Architecture. Retrieved July 05, 2017, from http://www.orissaculture.gov.in/Architecture.asp

Das, A. (2012, August 15). Kala Pahad-The Destroyer of Hinduism. Retrieved October 13, 2017, from http://amareshcd.blogspot.in/2012/o8/kala-pahad-destroyer-of-hinduism.html

Das, P. (2010, November 12). Devotees upset by theft of idols from Puri temple. The Hindu.

Department of Tourism, Government of Odisha. (n.d.). Mission $\mathcal{E}$ Vision. Retrieved October 18, 2017, from Odisha Tourism: http://www.odishatourism.gov.in/?q=node/26

Development Alternatives. (2012). Other Walling Materials: Laterite blocks. Retrieved July 04, 2017, from ecobrick: http://www.ecobrick.in/other_walling_material.aspx

Dubey, B. D. (2014, August 01). CBSE CLASS 10 HINDI GRAMMAR RAS (हिन्दी व्याकरण-रस): रस की परिभाषा. Retrieved October 18, 2017, from udadhi.com: http://www.udadhi.com/2014/o8/cbse-class-10-hindigrammar-ras.html

Dwyer, D. J. (2011, September 07). Rules Are Meant to Be Broken! Retrieved October 20, 2017, from https://www.psychologytoday.com/blog/got-minute/201109/rules-are-meant-be-broken

elevationmap.net: Worldwide Elevations. (n.d.). Elevation Search. Retrieved July 04, 2017, from http://elevationmap.net/4-lingaraj-nagar-old-town-bhubaneswar-odisha-751002india?latlngs $=(20.2382383,85.83375090000004)$

Encyclopædia Britannica, Inc. (2017, June 10). Krishna: Hindu Deity. Retrieved January 01, 2018, from https://www.britannica.com/topic/Krishna-Hindu-deity 
Eric Doehne, C. A. (2010). Stone Conservation: An Overview of Current Research. (A. Lucke, Ed.) Retrieved July 05, 2017, from http://www.getty.edu/conservation/publications_resources/pdf_publications/pdf/stoneconservation.pd $\mathrm{f}$

G.C.Chauley. (2004). Sun Temple of Konarak: History of Conservation and Preservation. New Delhi, India: Kaveri Book Service.

G.M.Bailey. (1979, December). Trifunctional Elements in the Mythology of the Hindu Trimūrti. Numen, 26(Fasc.-2), 152-163.

Geology.com. (2005-2017). Sandstone: What is Sandstone? Retrieved July 04, 2017, from http://geology.com/rocks/sandstone.shtml

George Hool, N. C. (May, 1918). Concrete Engineers' Handbook. New York, USA: McGraw-Hill Book Company, inc.

GhenNet. (2000, October 15). Why do we consider Tulsi sacred? Retrieved October 26, 2017, from Hindu FAQ: https://hindunet.org/faq/fom-serv/cache/19.html

GKToday. (2014, September 06). Kalinga School of Architecture. Retrieved November 24, 2017, from https://www.gktoday.in/gk/kalinga-school-of-architecture

Gonda, J. (2016). Visnuism and Sivaism: A Comparison. London, United Kingdom: Bloomsbury Academic.

google.co.in/maps. (2017). Search Google Maps. Retrieved July 04, 2017, from https://www.google.co.in/maps

Government of Odisha Information Technology Department. (n.d.). History: Medieval-1: 931 AD. Retrieved July 04, 2017, from Odisha Profile::

http://webcache.googleusercontent.com/search?q=cache:ewIGfit3KVIJ:www.odisha.gov.in/portal/View Details.asp\%3Fvchglinkid\%3DGLo12\%26vchplinkid\%3DPLo48\%26vchslinkid\%3DSLo2o+\&cd=5\&hl=en $\& \mathrm{ct}=\mathrm{clnk} \& \mathrm{gl}=\mathrm{in}$

Guardian News and Media Limited. (2017, August 15). India: the British Raj is dead - archive, August 1947. Retrieved January 01, 2018, from https://www.theguardian.com/world/2017/aug/15/india-pakistanindependence-guardian-editorial-1947

Gyan P. Nyaupane, D. J. (2010, April 12). Heritage awareness and appreciation among community residents: perspectives from Arizona, USA. International Journal of Heritage Studies, 16(3), 225-239.

HALLO-III, S. (2017, April 23). Plumbing Repair Tutorials: Working with PVC Pipe. Retrieved October 22, 2017, from The Spruce: https://www.thespruce.com/working-with-pvc-pipe-2718790

Harper Collins Publishers. (1853). Definition of 'handcraft'. Retrieved November 22, 2017, from https://www.collinsdictionary.com/dictionary/english/handcraft

Harris, N. (2007, December). Shame, ethical identity and conformity:Lessons from research on the psychology of social influence. Retrieved July 06, 2017, from Australian National University: http://regnet.anu.edu.au/sites/default/files/publications/attachments/2015-05/ROP12a_o.pdf

Hay, S. (Scratching the Surface). Sophie Hay:Just an archaeologist who lived in Rome. Retrieved July 26, 2017, from WordPress.com: https://pompei79.wordpress.com/2014/03/05/scratching-the-surface/

Indian History. (n.d.). Eastern Ganga Dynasty. Retrieved October 13, 2017, from http://gkforallexams.in/indianhistory/eastern-ganga-dynasty.aspx

indianmirror.com. (1999-2017). Orissa Stone Crafting. Retrieved July 04, 2017, from http://www.indianmirror.com/culture/indian-specialties/orissastonecrafting.html

INDIRA GANDHI NATIONAL CENTRE FOR THE ARTS. (n.d.). Documentation format for Archaeological/Heritage Sites/Monuments-Serial No.:OR/KDA/BSR-39. Retrieved October 20, 2017, from http://citeseerx.ist.psu.edu/viewdoc/download?doi=10.1.1.730.2308\&rep=rep1\&type=pdf

Indo-Asian News Service. (2016, April 25). Cracks Found In Jagannath Temple In Puri, Restoration Work Underway. NDTV, pp. https://www.ndtv.com/india-news/cracks-found-in-jagannath-temple-in-purirestoration-work-underway-1399210.

Ishta Devata. (2016). Chitrakarini Temple. Retrieved October 10, 2017, from https://www.ishtadevata.com/temple/chitrakarini-temple-bhubaneshwar-khurda/

J.P.Shrivastava, M. (2005, February). A review of research on Late Cretaceous volcanic-sedimentary sequences of the Mandla Lobe: implications for Deccan volcanism and the Cretaceous/Palaeogene boundary. Cretaceous Research, 26(1), 145-156. 
Jawaharlal Nehru National Urban Renewal Mission, Ministry of Urban Development. (2011). City Development Report: Annexure-3: Places of Tourists Importance in and around Bhubaneswar. Retrieved July 04, 2017, from http://jnnurm.nic.in/wp-content/uploads/2010/12/bhubneshwar_Annexure3.pdf

Jha, S. K. (2015). Sustenance of Languishing Traditional Crafts Through Design and Processes Interventions: Leather Toy Craft. In T. T. Amaresh Chakrabarti (Ed.), DS79: Proceedings of The Third International Conference on Design Creativity, Indian Institute of Science, Bangalore (pp. 356-363). Scotland: The Design Society.

Jha, S. K. (2017, April 20). Craft Study and Product Design Interventions: Soapstone Craft Cluster of Dhakotha Area in Kendujhar District of Odisha, India. The Chitrolekha Journal on Art and Design, o1(01), 10-36.

Kaufman, S. B. (2011, January 05). The Most Powerful Law of Attraction. (Sussex Publishers, LLC) Retrieved July 04, 2017, from Psychology Today: https://www.psychologytoday.com/blog/beautifulminds/201101/the-most-powerful-law-attraction

Lancashire, R. J. (2001-2008). Some chemistry of Iron. Retrieved August 2017, 02, from http://wwwchem.uwimona.edu.jm/courses/iron.html

Learn Oriya Online. (2016). Useful House Materials in Oriya Language. Retrieved July 05, 2017, from http://learnoriya.blogspot.in/2012/o3/useful-house-materials-in-oriya.html

Longjam Bedana, S. L. (2014, May). Search for Identity and Home in Buchi Emecheta's novel Second Class Citizen. IOSR Journal Of Humanities And Social Science, 19(5), 32-35.

Lotus Sculpture. (2000-2017). Hindu Goddess Saraswati the Goddess of Wisdom. Retrieved October 12, 2017, from Lotus Sculpture: https://www.lotussculpture.com/sarasvati.html

Madhupratap, M. (2003, March). Biogeochemistry of the Bay of Bengal: physical, chemical and primary productivity characteristics of the central and western Bay of Bengal during summer monsoon 2001. Deep Sea Research Part II: Topical Studies in Oceanography, 50(5), 881-896.

Ministry of Law and Justice, Government of India. (1958). THE ANCIENT MONUMENTS AND ARCHAEOLOGICAL SITES AND REMAINS ACT, 1958. Retrieved October 24, 2017, from http://lawmin.nic.in/ld/P-ACT/1958/A1958-24.pdf

National Archives of Mauritius, Republic of Mauritius. (2017, September 14). Conservation: (b.) Restorative conservation. Retrieved October 21, 2017, from http://nationalarchives.govmu.org/NationalArchivesServices/conservation.do

Orissa-Tourism.com. (2017). Mukteswara Temple. Retrieved October 13, 2017, from http://www.orissatourism.com/web/Attractions/TemplesMonuments/HinduTemples/MukteswaraTemple.aspx

Orissatourism.org. (2016). History of Bhubaneswar. Retrieved July 04, 2017, from http://www.orissatourism.org/travel-to-orissa/bhubaneshwar/history-of-bhubaneshwar.html

P.K.Devi. (2011). Monumental Neglect: Need for Awakening. Orissa Review.

Panda, N. (2011, October 12). Concrete threat to temple- Local residents have been maintaining ancient shrine for years. The Telegraph.

Patheos. (2013, August 06). Who Is Krishna? Retrieved December 29, 2017, from http://www.patheos.com/blogs/whitehindu/2013/o8/who-is-krishna

Portland Cement Association. (2017). How Cement is Made. Retrieved January 01, 2018, from http://www.cement.org/cement-concrete-applications/how-cement-is-made

Post News Network. (2016, April 26). Cracks found in temple, restoration underway. Orissa Post, pp. http://www.orissapost.com/cracks-found-in-temple-restoration-underway.

Praharaj, M. (2014, April 18). Konark Temple Conservation Demands Urgent Attention. The Pioneer, pp. http://www.dailypioneer.com/state-editions/bhubaneswar/konark-temple-conservation-demandsurgent-attention.html.

PRS Legislative Research. (2010, March 29). THE ANCIENT MONUMENTS AND ARCHAEOLOGICAL SITES AND REMAINS (AMENDMENT AND VALIDATION) ACT, 2010. Retrieved October 24, 2017, from http://www.prsindia.org/uploads/media/Acts/Ancient\%2oMonuments\%2oand\%20Archaeological\%2oS ites\%2oand\%2oRemains\%2oAct\%202010.pdf

R.M. Lemaire, M. T. (1981). CONSERVATION OF THE KONARAK TEMPLE, ORISSA. Paris, France: United Nations educational, Scientific and Cultural Organization. 
90 | The Chitrakarini Temple of Bhubaneswar (Odisha, India): An Investigative Field Study

Raj, K. (2009). The Mythical Naag-Devata (The Mythical Snake-God). Retrieved October 18, 2017, from Sulekha: http://creative.sulekha.com/the-mythical-naag-devata-the-mythical-snake-god_426933_blog

Raj, N. (2016, January 11). Approximately how many temples are there in Bhubaneswar? Retrieved November 07, 2017, from Quora: https://www.quora.com/Approximately-how-many-temples-are-there-inBhubaneswar

Rakesh, R. (2013, June 14). Why Shaiva and Vaishnava fight? Retrieved October 11, 2017, from Speaking Tree: https://www.speakingtree.in/blog/why-shaiva-and-vaishnava-fight

RESPECT WOMEN. (2014, January 17). My Mother, My First Teacher. Retrieved October 12, 2017, from Speak Out: http://respectwomen.co.in/my-mother-my-first-teacher

Richards, D. (April 2010). A CRITICAL ANALYSIS OF THE CLIFTON SUSPENSION BRIDGE. Proceedings of Bridge Engineering 2 Conference 2010 (pp. o1-10). Bath, UK: University of Bath.

Rinku Parashar, D. A. (March, 2016). Temples of Odisha- the Geometry of Plan Form. -International Journal for Innovative Research in Science \& Technology, 02(10), 117-121.

S.Malhotra. (2011). Geetopdesh: spirituality, cultural values and psychotherapy. ScienceDirect, $26,466$.

San, S. (2015, November 08). Chitrakari Temple-Bhubaneswar. Retrieved October 20, 2017, from YouTube: https://www.youtube.com/watch?v=RaGoaHKmRiI

Sanatan Sanstha. (2014, May 13). Offering Naivedya (Food offeredto the Deity as part of ritualistic worship). Retrieved July 17, 2017, from http://www.sanatan.org/en/a/214.html

Sanatan Society. (2017). Saraswati. Retrieved November 24, 2017, from http://www.sanatansociety.org/hindu_gods_and_goddesses/saraswati.htm

School of Architecture \& Design, The University of Kansas. (2017, March 28). Architecture Prof. Silva Shares Why Saving Historic Buildings Requires Local Community Support. Retrieved October 26, 2017, from Architecture Department: https://architecture.ku.edu/prof-silva-shares-why-saving-history-requireslocal-community-support

Shawe, D. R. (1968). Petrography of Sedimentary Rocks in the Slick Rock District, San Miguel and Dolores Counties, Colorado. U.S. Atomic Energy Commission. WASHINGTON: UNITED STATES GOVERNMENT PRINTING OFFICE.

Shepherd, L. (2017, April o1). Ways to Measure Without Needing a Ruler. Retrieved June 17, 2017, from https://www.thespruce.com/ways-to-measure-without-ruler-2366642

Sirisrisak, T. (2009, October). Conservation of Bangkok old town. Habitat International, 33(4), 405-411.

Sivanand, S. (1996). LORD SIVA AND HIS WORSHIP (o8th ed.). Tehri-Garhwal, Uttar Pradesh, India: The Divine Life Trust Society.

Soifer, D. A. (1991). The Myths of Narasimha and Vamana: Two Avatars in Cosmological Perspective. New York, USA: State University of New York Press.

Sri Radha Mahalkshmi Ashram, Vrindaban, India. (2002, December 16). An Endless Divine Continuity-Part 8: SAKHI'S SWEETNESS: Guntur Ashram. Retrieved November 22, 2017, from http://www.sriradha.org/nannatho8/nannatho8_5.html

Srinivasji. (2017, March 09). Lingaraj Temple-Bhubaneswar : History E mythological significance. Retrieved July 04, 2017, from Guide of Hinduism: http://srinivassharma.com/lingaraj-temple-bhubaneswar

Sumanta Sanyal, Encyclopedia Mythica. (1997, March 03). Garuda. Retrieved October 21, 2017, from MCMXCV-MMIX Encyclopedia Mythica: http://www.pantheon.org/articles/g/garuda.html

Thakur, P. (2016, February 25). 10 unknown stories of Lord Shiva. Retrieved July 05, 2017, from http://www.speakingtree.in/allslides/10-controversial-stories-of-lord-shiva

tellyupdates.com. (2016, September 03). congruency vs similarity-vimala-nagalakshmi. Retrieved November 24, 2017, from Episodic Analysis: www.tellyupdates.com

The Bhaktivedanta Book Trust International, Inc. (2002-2015). Radha, Krishna's Female Counterpart. Retrieved December 30, 2017, from http://www.krishna.com/radha-krishnas-female-counterpart

The Hindu. (2002, December 27). Glorious synthesis of temple styles. Retrieved August 11, 2017, from The Hindu: Entertainment: http://www.thehindu.com/thehindu/fr/2002/12/27/stories/200212270157100o.htm

The International Society for Krishna Consciousness (ISKCON). (2014). What is Vaishnavism? Retrieved October 12, 2017, from http://www.iskcon.org/what-is-vaishnavism 
UNESCO World Heritage Centre. (1992-2017). Ekamra Kshetra-The Temple City, Bhubaneswar. Retrieved July 05, 2017, from http://whc.unesco.org/en/tentativelists/5916

Verma, S. (2014, February 21). The Kurukshetra War in Mahabharat: A Day-by-Day Account. Retrieved December 30, 2017, from All About Bharat: http://www.allaboutbharat.org/post/kurukshetra-warmahabharata

Water Policy International Ltd. (2000-2001). Water in Religion. Retrieved August 01, 2017, from The Water Page: http://www.africanwater.org/religion.htm

Wikimedia Foundation, Inc. (2017, November 05). Bhajan. Retrieved November 23, 2017, from https://en.wikipedia.org/wiki/Bhajan

Wikimedia Foundation, Inc. (2017, October 12). Brahma. Retrieved October 12, 2017, from https://en.wikipedia.org/wiki/Brahma

Wikimedia Foundation, Inc. (2017, June o1). Chisel. Retrieved July 05, 2017, from https://en.wikipedia.org/wiki/Chisel

Wikimedia Foundation, Inc. (2017, April 02). Kalinga architecture. Retrieved July 05, 2017, from https://en.wikipedia.org/wiki/Kalinga_architecture

Wikimedia Foundation, Inc. (2017, July 02). Narasimhadeva I. Retrieved July 05, 2017, from https://en.wikipedia.org/wiki/Narasimhadeva_I

Wikimedia Foundation, Inc. (2017, September 07). Narasimhadeva I. Retrieved October 13, 2017, from https://en.wikipedia.org/wiki/Narasimhadeva_I

Wikimedia Foundation, Inc. (2017, November 20). Saraswati. Retrieved November 22, 2017, from https://en.wikipedia.org/wiki/Saraswati

Wikimedia Foundation, Inc. (2017, October 09). Shaivism. Retrieved October 12, 2017, from https://en.wikipedia.org/wiki/Shaivism

Wikimedia Foundation, Inc. (2017, May 30). Yameshwar Temple. Retrieved July 04, 2017, from https://en.wikipedia.org/wiki/Yameshwar_Temple

Wikiwand. (2017). Eastern Ganga dynasty. Retrieved October 13, 2017, from http://www.wikiwand.com/en/Eastern_Ganga_dynasty

Wiktionary. (2017, June 25). Paintress. Retrieved October 12, 2017, from https://en.wiktionary.org/wiki/paintress

Wiktionary. (2017, May 22). Wiktionary:Welcome, newcomers. Retrieved October 12, 2017, from Wiktionary:About: https://en.wiktionary.org/wiki/Wiktionary:Welcome,_newcomers

WildFilmsIndia. (2013, April 18). Restoration of Lingaraj Temple underway in Bhubaneshwar, Orissa. Bhubaneshwar, Odisha, India: Youtube.com. Retrieved October 13, 2017, from https://www.youtube.com/watch?v=30onBCCzBMc

WordPress.com. (2016, June 20). Urmila(Lakshmana's wife)- The Lost Heroine. Retrieved November 24, 2017, from https://srilakshmio7.wordpress.com/2016/06/20/urmillalakshmanas-wife

Yadav, O. P. (2015, October 27). Eradication Of Plants And Trees From Historic Buildings And Monuments. (D. M. Turin, Ed.) Ancient Nepal, 28-32.

मुक्त ज्ञानकोश विकिपीडिया. (2017, October 19). दीपावली. Retrieved October 21, 2017, from https://hi.wikipedia.org/wiki/दीपावली 